Portland State University

PDXScholar

Spring 9-21-2017

\title{
Loanwords in Context: Lexical Borrowing from English to Japanese and its Effects on Second- Language Vocabulary Acquisition
}

Andrew Michael Sowers

Portland State University

Follow this and additional works at: https://pdxscholar.library.pdx.edu/open_access_etds

Part of the Applied Linguistics Commons, and the First and Second Language Acquisition Commons Let us know how access to this document benefits you.

\section{Recommended Citation}

Sowers, Andrew Michael, "Loanwords in Context: Lexical Borrowing from English to Japanese and its Effects on Second-Language Vocabulary Acquisition" (2017). Dissertations and Theses. Paper 3970. https://doi.org/10.15760/etd.5865

This Thesis is brought to you for free and open access. It has been accepted for inclusion in Dissertations and Theses by an authorized administrator of PDXScholar. Please contact us if we can make this document more accessible: pdxscholar@pdx.edu. 
Loanwords in Context:

Lexical Borrowing from English to Japanese and its Effects on SecondLanguage Vocabulary Acquisition

\author{
by \\ Andrew Michael Sowers
}

A thesis submitted in partial fulfillment of the requirements for the degree of

\author{
Master of Arts \\ In \\ Teaching English to Speakers of Other Languages
}

Thesis Committee:

Lynn Santelmann, Chair

Susan Conrad

Patricia Wetzel

Portland State University

2017 
(C) 2017 Andrew Michael Sowers 


\begin{abstract}
Research has shown that cognates between Japanese and English have the potential to be a valuable learning tool (Daulton, 2008). Yet little is known on how Japanese learners of English produce cognates in context. Recently, studies have argued that cognates can cause a surprisingly high number of syntactic errors in sentence writing activities with Japanese learners (Rogers, Webb, \& Nakata, 2014; Masson, 2013). In the present study, I investigated how Japanese learners of English understood and used true cognates (words that have equivalent meanings in both languages) and non-true cognates (words where the Japanese meaning differs in various ways from their English source words). Via quasi-replication, I analyzed participants' sentences to determine the interaction of true and non-true cognates on semantics and syntax. In an experimental study, twenty Japanese exchange students filled out a word knowledge scale of thirty target words (half true cognates and half non-true cognates) and wrote sentences for the words they indicated they knew. These sentences were analyzed quantitatively and qualitatively for both semantic and syntactic errors. Sentences with true cognates were semantically accurate $86 \%$ of the time, while those with non-true cognates were accurate only $62.3 \%$ of the time, which was a statistically significant difference. When the sentences were analyzed for syntax, there was no statistically significant difference in the number of errors between true and non-true cognates, which contrasts with previous research. Qualitative analysis revealed that the most problematic syntactic
\end{abstract}


issue across both cognate types was using collocations correctly. Among those collocational issues, there were clear differences in the types of errors between true and non-true cognates. True cognate target words were more likely to lead to problems with prepositional collocations, while non-true cognate target words were more likely to lead to problems with verb collocations. These results suggest that for intermediate Japanese learners of English, semantics of non-true cognates should be prioritized in learning, followed by syntax of true and non-true cognates, which should be taught according to the most problematic error types per cognate status. 


\section{Acknowledgments}

I would like to express sincere thanks to all the students and staff at the Aeon Mizonokuchi Eikawa branch in Kawasaki, Japan. This was a close-knit Japanese community that welcomed me and taught me great deal about language, culture, and life.

I would also like to thank my parents, Mike and Cathy, for encouraging me to travel abroad and excel in academia.

In addition, I am grateful for the support of my Japanese informants Kiyomi Stevens and Mizuki Okano. Without them, target word selection and inter-rater reliability for the present study would not have been possible.

Finally, I would like to thank my committee- Dr. Lynn Santelmann, chair, for her efficiency and quick study with the data at hand; Dr. Susan Conrad, for her honesty and professionalism; and Dr. Patricia Wetzel, for her provision of authenticity surrounding Japanese language and culture. 


\section{Table of Contents}

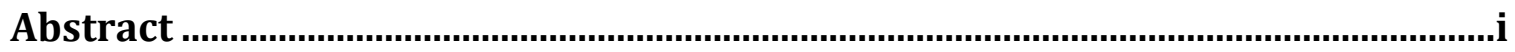

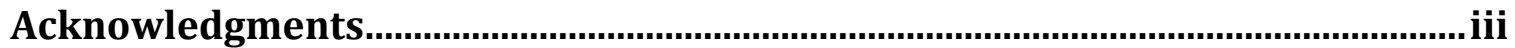

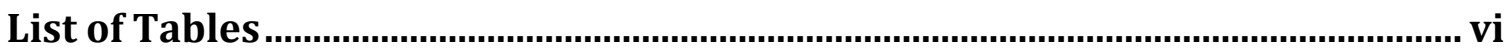

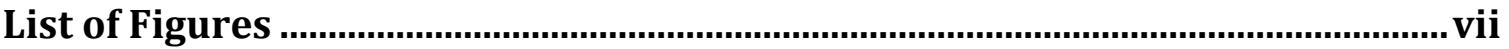

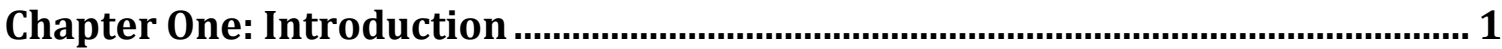

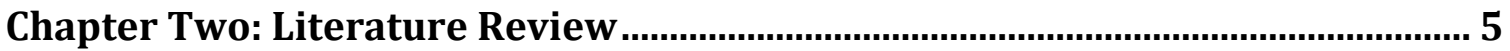

2.1 The Psycholinguistic and Affective Support Provided by Cognacy, and the Lack

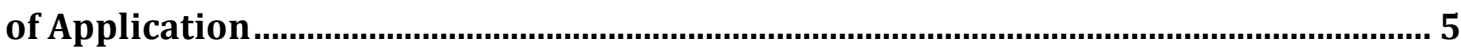

2.2 What is Currently Known about Japanese/English Cognates................................. 8

2.3 The Need for Further Contextualized Cognate Research ..........................................12

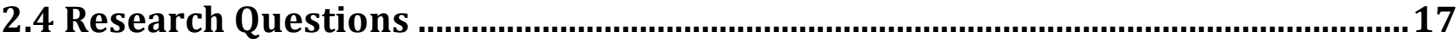

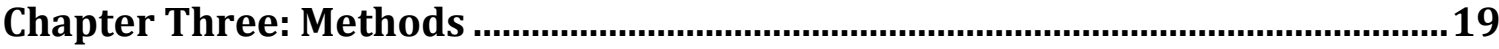

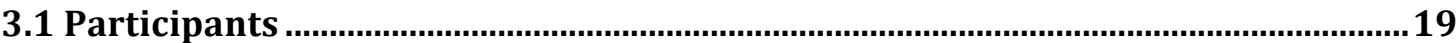

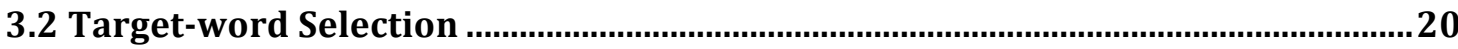

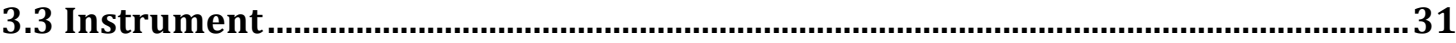

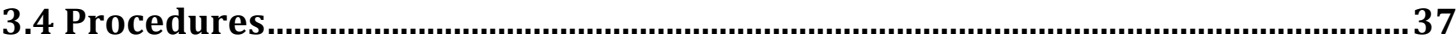

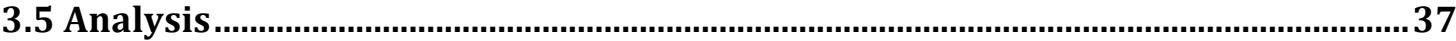

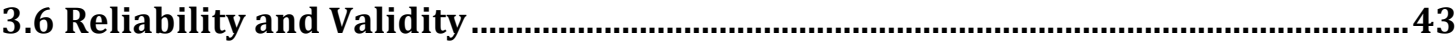

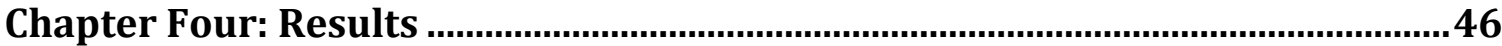

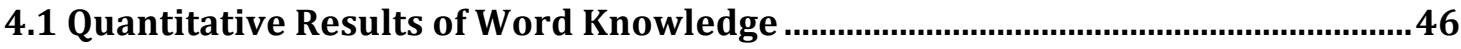

4.2 Quantitative Results of Sentence Semantics ........................................................... 


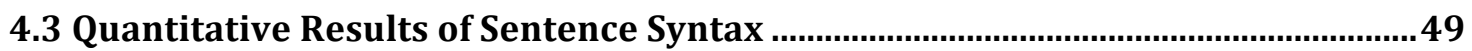

4.4 Qualitative Results of Sentence Semantics ........................................................50

4.5 Qualitative Results of Sentence Syntax …........................................................... 55

Chapter Five: Discussion and Conclusion .............................................................65

5.1 Discussion of Findings per Research Question .........................................................66

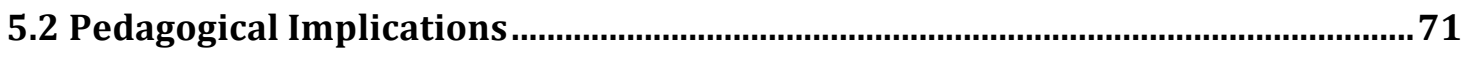

5.3 Limitations, Areas for Future Research, and Conclusion........................................ 80

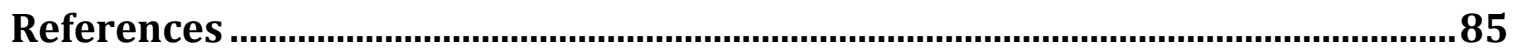

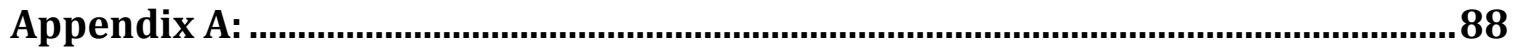

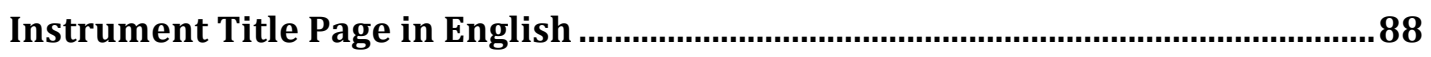

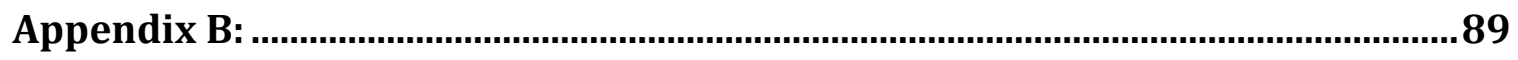

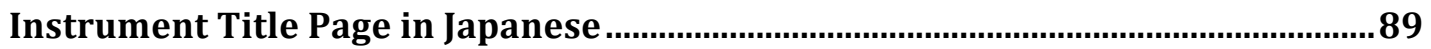

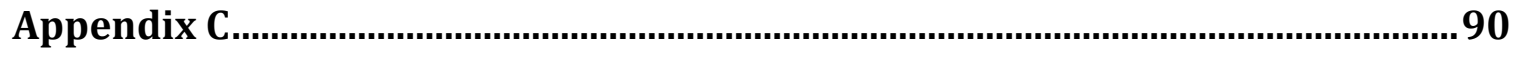

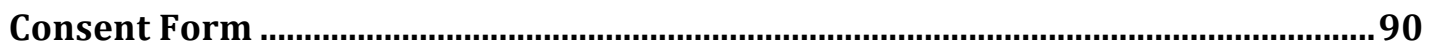




\section{List of Tables}

Table 1

Taxonomy of Semantic Learnability of Japanese/English Cognate Types............10

Table 2

Sub-categorizations of Non-true Cognate Target Words.

Table 3

Lexical Word Classes of All Target Words

Table 4

Verb-Collocational Status in Japanese.

Table 5

Differences in Word Knowledge Scale from Masson's (2013) to Present Study...33

Table 6

Participants' Declaration of Word Knowledge per Cognate Status.

Table 7

Semantic Evaluation of Participants' Sentences per Cognate Status.

Table 8

Syntactic Evaluation of Participants' Sentences per Cognate Status.

Table 9

Examples of L1 interference in Participants' Sentences.

Table 10

Examples of Slightly Incorrect Participant Sentences

Table 11

Total Semantic Error Types per Cognate Status.....................................................54

Table 12

Error Types that Comprised Each Syntactic Error Category. 57

Table 13

Total Syntactic Error Types per Cognate Status. 
Table 14

Sub-categorizations of Collocational Errors per Cognate Status............................61

Table 15

Recommended Curriculum Flow for Teaching True and Non-true Cognates.......73

\section{List of Figures}

Figure 1

Collapsed categories of loanwords for the present study

Figure 2

Process for analyses of responses for Answer 3 of Word Knowledge Scale..........40

Figure 3

Personal Terminology Checklist, adapted from Riley and Sours (2014) 


\section{Chapter One: Introduction}

One may not think that two languages as dissimilar as English and Japanese share much commonality. With the significant number of English lexical items that have been loaned into Japanese over the previous two centuries, however, there has been increasing interest in the interplay of this shared lexicon between the two languages. Of the top 3,000 high-frequency English lexical items, 45\% of these have some cognate in Japanese (Daulton, 2003). This number is quite striking considering not only the vast orthographic, phonological, and grammatical differences between English and Japanese, but also the fact that they come from different language families. English borrowings are pervasive and abundant in Japan. According to Stanlaw (2004), “Japanese today cannot adequately be spoken without the use of English loanwords or English-based vocabulary items" (p. 2). One recently published dictionary of gairaigo (Japanese words loaned from abroad) consisted of 50,000 such words in the Japanese lexicon. It has even been estimated that about $10 \%$ of the modern Japanese lexicon stems from the English language (Daulton, 2011).

As a beginning student of Japanese living in Japan, I was able to harness this shared lexicon via my own first language (L1) reserve of English vocabulary. Once a native English speaker possesses an understanding of Japanese's katakana writing system (the syllabary reserved specifically for loan words), one is generally able to guess at certain Japanese meanings with a high degree of success. To illustrate, 
コーヒ, here written in katakana, is read as kouhi, which is semantically identical with and phonologically very similar to the English word coffee. The same can be said for numerous other high-frequency Japanese words: ニュース, pronounced nyuusu, from the English word news, レストラン, pronounced resutoran, from restaurant, and パーティー, pronounced paati, from party are just a few examples from everyday vocabulary. Given the direct semantic similarity of these borrowings, it is clear to see how these words could ease the learning burden for Englishspeaking students of Japanese.

Yet there are also borrowings into Japanese that often confound native English speakers. This phenomenon has been documented by other researchers. According to Daulton (2008), "In most cases, native speakers will typically experience confusion in Japan, as a fairly detailed acquaintance with the details of modern Japanese urban life is necessary to fully understand loanwords" (p.21). I was surprised to learn that サービス/saabisu or service means free of charge in Japanese. One of my favorite ramen restaurants in Mizonokuchi used to offer サービスチキン/saabisu chikin (service chicken), where customers were invited to top off their bowls from endless amounts of plates of fried chicken that were provided at the countertop. While saabisu is a borrowing from English, the semantic properties of this word are quite different in Japan. Service does not ever mean free of charge in English, and it took the explicit explanation of a friend to help me overcome this point. A second non-true cognate that I encountered was マンション 
/manshon, from the English word mansion. Manshon in Japanese does not mean a large house owned by a wealthy person, but instead denotes an apartment complex. This word became especially amusing for me as I corresponded with American friends and family, informing them that I now lived in a Tokyo mansion! A final example of a non-true cognate that I encountered was in the workplace. As I had put in five years of service of with a Japanese company, I was often asked by my manager to train and support new teachers. Ono-san directed me to, “フォローして 下さい,/foro shitte kudasai (please follow them) as new staff became acquainted with our school's teaching philosophy and day-to-day business operations. Was I to follow the new teachers around all day and shadow their every movement? In fact, I came to learn that the Japanese word フォロー/foro is a back-clipping of the English phrase follow up, and has taken on the Japanese meaning of support, or cover for. Thus, while many loans are quite helpful for learners between Japanese and English, there are also instances where confusion ensues.

My primary purpose for being in Japan was not as a student of Japanese, but as an English teacher. As I grappled with the inconsistencies and idiosyncrasies of the Japanese language, I naturally could not help but wonder how these shared words might be of use to, or confound, my students. Was there a way to acquire these words beyond incidental learning? Could they be used in the classroom? For the present study, I analyzed the situation from the perspective of Japanese L1 speakers who are learning English in the United States. I wanted to know how L1 knowledge of Japanese affects learners' acquisition of English words, specifically 
those English words that have been borrowed into and/or undergone semantic drift in the Japanese language. I wanted to find out which words would be helpful, which would be harmful, and how thoroughly learners knew these words when it came to productive language use. Therefore, I designed a study that shed light on cognates in the interlanguage of Japanese learners of English. It is my intention that the results of this research may eventually be applied in a formal pedagogical environment. 


\section{Chapter Two: Literature Review}

In this chapter, I will first provide background on what is known about the support that cognates can provide to second language (L2) learning at large. Much work has been done in this area, across a wide range of languages. Next, I will highlight the research on cognate learning between English and Japanese specifically. The focus will primarily be on the semantic differences between the two languages, as that is what has been the focus of most studies. Finally, I will draw attention to a gap in the existing literature- contextualized learning of cognates between English and Japanese, and demonstrate the need to pursue this research further.

\subsection{The Psycholinguistic and Affective Support Provided by Cognacy, and the Lack of Application}

Considerable research has been conducted regarding the linguistic support found in cognacy. Though sometimes confusing, cognates can generally be helpful in learning new vocabulary (Nation, 2001). A new L2 word that looks and behaves orthographically and/or phonetically like a word in one's L1 is more likely to be grasped and recalled quickly. In a study of English-Dutch learners, Bultena, Dijkstra and van Hell (2014) acknowledged, "the combination of meaning and form overlap gives rise to a cognate facilitation effect, which entails that cognates are processed faster and with fewer errors than noncognate words" (p. 1215). Similarly, in their study of Spanish-speaking learners of English, Kelley and Kohnert (2012) wrote, "when cognates are present, proficiency in one language can assist with 'meaning- 
making' in an unfamiliar language" (p. 191). Montelongo \& Hernandez (2013) echoed this claim from their work with Latino learners of English: "Teaching Latino ELs [English Learners] about cognates taps into their preexisting knowledge and enables them to engage with literacy more effectively than strategies that ignore or denigrate the linguistic knowledge EL students bring to the classroom" (p. 188). Indeed, learners may often know a new word simply by virtue of the fact that this word exists in their L1.

Further research has revealed that many teachers and learners have a positive impression of cognacy. Champ's (2014) corpus analysis of Japanese textbooks for English speaking learners of Japanese found that gairaigo words (Japanese vocabulary stemming from predominantly English loans) were used more frequently in beginner-level textbooks than at the advanced levels. The author posited that this was likely due to cognacy characteristics of loanwords feeling less intimidating to students studying Japanese. In the qualitative portion of the same study, Champ's (2014) interviews revealed that many teachers believed their students viewed gairaigo as fun, interesting, and a source of motivation. Similarly, Daulton (2008) commented, "naturally, the ease of cognates supports the larger picture of learner motivation" (p. 124). Cognates are likely beneficial to students precisely because they ease the learning burden by feeling familiar.

Although there is evidence pointing to the psycholinguistic and motivational support that cognates can provide, these words have rarely been utilized in formal pedagogical settings. It seems that educators may be squandering an important 
opportunity to apply the given research. Across a range of ESL and EFL contexts for leaners of different L1s, Rogers, Webb and Nakata (2014) have noted, “Despite research demonstrating pedagogically significant numbers of cognates shared between languages, and researchers advocating teaching cognates to speed up vocabulary learning, there is little focus on formal and semantic similarity between languages in teaching materials" (p. 11). This claim has also been substantiated specifically for the case of Japanese learners. According to Daulton (2008), "While most researchers and educators in the West recognize that cognates are a helpful resource for learners, within Japan, a strong bias against English-based loanwords persists" (p. 61). Reasons for this bias are likely rooted in the unique loans that have changed meaning upon entering Japanese- "the anecdotal condemnation of certain cognates has often led to guilt be association of all" (p. 57). Educators are wary of using any loanwords because certain loanwords may cause confusion. What is needed is a finer understanding of all types of cognates between English and Japanese. From there, more precise pedagogical materials may be created which address specific learning difficulties per cognate type.

Though orthographic, phonetic, and semantic differences have been the focus of most research on Japanese-English cognates, there is much more to the picture. In fact, these lexical items have rarely been fully scrutinized in a manner that would be valuable to developing learners' complete understanding of what it truly means to acquire vocabulary. Nation (2013) outlined the three aspects of what is involved in knowing a word: form, meaning, and usage. Presently, research on Japanese- 
English cognates has largely been confined to the first two aspects. The present study addresses this gap on usage, and extends the holistic picture of cognate learning into using words in context.

\subsection{What is Currently Known about Japanese/English Cognates}

First a word on nomenclature- while the term cognate can have various interpretations, this study will operationalize this term based on the liberal definition proposed by Rogers, Webb and Nakata (2014):

Cognates will be defined as word pairs that are shared across languages that are similar or the same in form and semantics regardless of the absence or presence of a common ancestor...the rationale being that such a definition opens up the discussion to historically unrelated languages that share words through borrowing. (p. 10)

Because English and Japanese are historically unrelated and share no common ancestor languages, the above definition will better fit the purposes of this study. Just as the English word perfect and the Spanish word perfecto are cognates stemming from Latin, the English word design, and its Japanese equivalent, デザイン (dezain), will also be treated as cognates.

Lexical borrowing between English and Japanese occurs for a variety of pragmatic and sociolinguistic reasons including neologisms, prestige, pejoration, internationalization, technical jargon, scientific jargon, academic jargon, and mass 
marketing (Daulton, 2008; Hogan, 2010; Mckenzie, 2008). While English contains borrowings from Japanese-tsunami, karaoke, tycoon, the vast majority of lexical exchange between these two languages has flowed the other direction.

Japanese has borrowed from English in waves overtime. From the opening to western trade of the insulated Asian island in the 1860s, to the closing off of western borrowings during WWII, followed by the subsequent reopening and welcoming of American culture in the latter half of the $20^{\text {th }}$ century, a significant portion of the Japanese lexicon now stems from the English language (Hogan, 2010). When words are borrowed, they undergo phonetic and phonological changes to fit with the Japanese sound system, and reappear in the form of katakana charactersthe jagged and simple lines that constitute one of three scripts in Japanese.

In addition to phonetic/phonological change, cognates can also undergo semantic change. To date, considerable research has been conducted on the semantic properties of Japanese-English loanwords, and a continuum of helpfulness toward the learnability of these words has been found. Some Japanese words are identical in meaning to their English counterparts, while others have undergone drastic changes. Table 1 below, originally proposed by Uchida, can also be found in Daulton (2008) and Masson (2013). The table has been adapted and expanded here for comprehensibility. 
Table 1

Taxonomy of Semantic Learnability of Japanese/English Cognate Types

\begin{tabular}{|c|c|c|}
\hline Cognate Type & $\begin{array}{c}\text { Japanese kana and English } \\
\text { transliteration }\end{array}$ & $\begin{array}{c}\text { Explanation of semantic } \\
\text { difference }\end{array}$ \\
\hline True Cognate & $\begin{array}{l}\text { インターネット } \\
\text { intaanetto }\end{array}$ & $\begin{array}{l}\text { Intanetto in Japanese } \\
\text { means internet; no } \\
\text { semantic change. }\end{array}$ \\
\hline Convergent Cognate & $\begin{array}{l}\text { ツナ } \\
\text { tsuna }\end{array}$ & $\begin{array}{l}\text { Tsuna ony refers to canned } \\
\text { tuna in Japan. 鮁/Maguro } \\
\text { denotes live fish and sushi. } \\
\text { Thus multiple Japanese } \\
\text { words have converged onto } \\
\text { one single English word. }\end{array}$ \\
\hline Divergent Cognate & $\begin{array}{l}\text { パート } \\
\text { paato }\end{array}$ & $\begin{array}{l}\text { Paato means segment/ } \\
\text { section in Japanese, yet is } \\
\text { also a back-clipping of part- } \\
\text { time job. These two } \\
\text { meanings diverge into } \\
\text { separate words in English. }\end{array}$ \\
\hline Distant False Friend & $\begin{array}{c}\text { メンタリティー } \\
\text { mentaratii }\end{array}$ & $\begin{array}{l}\text { Mentaritii in Japanese } \\
\text { means intelligence, a } \\
\text { distant meaning from its } \\
\text { English counterpart. }\end{array}$ \\
\hline $\begin{array}{c}\text { Wasei-Eigo } \\
\text { ("Japanized English”) }\end{array}$ & $\begin{array}{l}\text { ベビカー } \\
\text { bebi kaa }\end{array}$ & $\begin{array}{l}\text { Bebi kaa_baby car) in } \\
\text { Japanese means baby } \\
\text { stroller. This term was } \\
\text { invented in Japan and is not } \\
\text { used in English. }\end{array}$ \\
\hline Close False Friend & $\begin{array}{l}\text { デモ } \\
\text { demo }\end{array}$ & $\begin{array}{l}\text { Demo is a back-clipping of } \\
\text { political demonstration. } \\
\text { Demo does not mean } \\
\text { protest in English, yet the } \\
\text { intra-lingual meanings are } \\
\text { closely related. }\end{array}$ \\
\hline
\end{tabular}

Note. Read from top to bottom, cognate types move from easiest to learn, to most difficult to learn. Adapted from Uchida (as cited in Daulton, 2008; Masson, 2013). 
From top to bottom, Table 1 moves from the most helpful loanwords to the least helpful in terms of semantic similarity. At the top of the scale, True cognates are word pairs that are the most semantically similar. There is no change in meaning from English as the word is taken on in Japanese. True cognates are words such as インターネット/intaanetto (internet), and タクシ/takushii (taxi). These words are helpful because learners already know the meanings in their L1. True cognates are often the semantic category of technical, scientific, and academic vocabulary. These types of borrowings typically undergo little semantic drift when making the leap from donor language to borrower language. According to Daulton (2005), "due to internationally defined and accepted standards, academic words in English and Japanese are likely to share meanings, as with technical and scientific terms" (p. 12). For experts to be able to communicate with other international experts in their fields, they must be able to agree on shared standards. Thus, with respect to pure word-level semantics, learners are generally able to trust their instincts when it comes to academic, scientific, and technical vocabulary.

The categories at the bottom of the scale, in contrast, are the most semantically dissimilar between English and Japanese (Daulton, 2008). Close false friends look like actual English words, yet take on different meanings in Japanese. デモ/demo means political protest, スマート/sumaato (smart) means slim, and クレーム/kureemu (claim) means complaint. These words are particularly difficult for learners because they are similar in form (after accounting for phonetic/ phonological change), and diverge only in meaning. Because these items look like 
English words and are written in the Japanese katakana syllabary reserved specifically for loan words, it is understandable that they could cause confusion for learners. Japanized English, the category second from the bottom, can also be difficult for learners. These are words that have been created in Japan for Japanese purposes, and are also known as 和製英語/wasei-eigo (和製/wasei meaning Japanese made + 英語/eigo meaning English). On the surface, wasei-eigo words resemble English words, yet would actually be unrecognizable to fluent English speakers who are unfamiliar with Japanese. These are items like ベビカー/bebii kaa (baby car), meaning baby stroller, バイキング/baikingu, meaning buffet (from the Scandinavian-themed viking instead of the more-difficult-to-pronounce smorgasbord), and ラブホテル/rabu hoteru (“love hotel”), meaning a type of hotel rented by the hour for short-term sexual rendezvous. As can be observed from these varied types of loans, the learning support that Japanese/English cognates provide is not always a straightforward process. There is not just one type of cognate, but rather a nuanced and multifaceted range.

\subsection{The Need for Further Contextualized Cognate Research}

It is no secret that there have been failures with English education in Japan. According to Daulton (2008), “Japan is among the world's monolingual societies where English-speaking visitors have great difficulty communicating...and ranks near the bottom of nations in TOEFL scores" (p. 2-3). Much of this failure has been 
the result of misguided teaching techniques, which prioritize entrance-exam scores and grammar-translation (Daulton, 2008). To that end, Japanese students rarely have the opportunity to practice productive skills. According to Thompson (2001) "The traditional Japanese regard for authority and formality is in tune with teacherdominated lessons where much heed is paid to the 'correct' answer, learning of grammar rules and item-by-item (rather than contextualized) vocabulary" (p. 309). To date, most research on Japanese-English cognates has been studied under similar assumptions, and tables like Uchida's are only valuable when it comes to decontextualized measurements of word knowledge.

A narrow focus on decontextualized one-to-one meaning relationships paints an incomplete picture of cognacy learning, however. According to Rogers, Webb, and Nakata (2014), "in the earlier studies, the tests assessing learning were always decontextualized translation tests. While these tests are useful, they do not indicate whether learners may be able to successfully use these cognates" (p. 12). This observation led those authors to focus their own study on this previously overlooked phenomenon: "Thus, it may be useful to measure the effects of cognacy with tests that require participants to use words in context" (p. 12). By analyzing learners' sentences that use cognates, the authors' exploration into contextualizaton found that cognates are actually more likely to create errors in learners' syntactic output than non-cognates. This finding is important as it reveals that even the most trusted cognates may not be "out of the woods" when it comes to easing the learning burden. 
Masson's (2013) study of Japanese learners' acquisition of English cognates took an even narrower view. Instead of comparing syntax of cognates against noncognates, Masson compared true cognates (those with the same meaning in both languages) against non-true cognates (those whose meaning has changed between the two languages). All words in the study were cognates that could be located at some point along Uchida's exhaustive spectrum (Table 1). The analysis of participants' sentences revealed that true cognates could be more confusing than had been previously thought. That is, when analyzed in a contextualized versus decontextualized manner, students were more likely to produce syntactic errors with true cognates than non-true cognates. The words that were the most semantically similar yielded the highest number of syntactic errors. In a review of Masson's study, Nation (2013) commented, "this is a very interesting finding- what we are most confident about is our biggest weakness" (p.34). This finding was especially meaningful as it brought to light that the ostensibly easiest words to acquire out of context might actually be one of the most difficult to use in context. Although Masson was able to point out this previously unnoticed aspect of Japanese-English cognate learning, there were also certain methodological limitations to that study, all of which can all be found in the survey format. Masson's (2013) word knowledge scale appeared as follows: 
(1) I don't know this word

(2) I've seen this word and I know one meaning

(3) I know more than one meaning of this word and I can write a sentence using this word

The above scale had three problematic issues: First- participants were asked to choose between Answer (2) knowing one meaning of a word and Answer (3) knowing more than one meaning (and being able to use the word in a sentence). There was no choice for participants to provide just one meaning and write a sentence. Thus, even if a participant knew only one meaning and could write a sentence with the word, potential data may have been lost due to the lack of answer choices. Though it is possible that all of the words chosen for the survey had multiple meanings, the target word selection process was left unclear in the study. Second - it was not clear if participants had to write a sentence even if they selected Answer (1). Participants may have declared I don't know this word, yet they still may have been required to write a sentence, which was then evaluated for its syntactic accuracy. If this were the case, then syntactic accuracy judgments were likely skewed. It would be quite difficult to measure a learner's contextualization of a word if they did not properly understand the meaning. This process for which answer choices required writing a sentence was also left unanswered in that study. Third-receptive and productive measurements were collapsed into a single category of Answer (3): I know more than one meaning of this word and I can write a sentence using this word. Participants had to choose between knowing the meaning 
of a word and declaring that they could write the word in a sentence, or not knowing either the meaning or how to write a sentence. As Nation (2013) commented on this answer's format:

Their choice is both or none. Two tests are being compared here. The scale test which is a recall test of receptive knowledge, and a productive recall test of the use of the word. There should be some agreement between the tests but they are testing rather different things...We have a difference of formats and a difference of types of knowledge (p. 35).

The root of the problem for Answer (3) is that a participant may have only known half of the answer (receptive or productive knowledge). If a participant only knew the meaning, but could not write the word in a sentence, then there is strong chance that the sentence syntax would have been incorrect. Conversely, if a learner only knew how to write the word in a sentence (which could occur through morphological guesswork pertaining to lexical word class), then it would be unclear if the learner truly understood the meaning of the word. It was left unclear whether syntax was graded as correct even if a participant failed to demonstrate correct knowledge of meaning.

Due to the limitations of Masson's (2013) study, but also the potential importance of the findings on true cognates, there is a need to investigate the issue with more rigor. If the results of Masson's study are to influence educators' understanding of cognate acquisition, then we must be sure that those results are 
accurate. Thus, the present study controlled for the aforementioned variables in order to test Masson's (2013) findings.

The recent findings that cognates create more syntactic difficulty than noncognates (Rogers, Webb, \& Nakata, 2014) and that true cognates create more syntactic difficulty than non-true cognates (Masson, 2013) are important because they draw attention to a previously overlooked aspect of Japanese-English borrowings - usage within context. The types of errors uncovered through these recent studies were only observable by measuring learner's output in the form of sentences. Rogers, Webb and Nakata (2014) hinted at an eventual outcome of their research. They pointed out that, "any teaching approach that prioritized the learning of cognates should place emphasis on providing repeated opportunities to encounter and use them in context" (p. 15). While the majority of the existing research surrounding cognates pertains to meaning acquisition via decontextualized discrete point tests, little work, other than Masson's (2013), and Rogers, Webb and Nakata's (2014) has been done that focuses on word usage in context. Given the recent nature of, and methodological limitations to these findings, further research is warranted in order to provide educators with a fuller picture of the specific learning difficulties inherent to this interesting class of words.

\subsection{Research Questions}

The present study builds upon the existing research on semantics, and further delves into the newly established territory of syntactic difficulties with 
cognates. This study was born out of two recent studies (Masson, 2013; Rogers, Webb, and Nakata, 2014) that made novel contributions to an evolving understanding of Japanese-English cognate learning. Specifically, Masson's (2013) methods were adapted and improved upon in order to answer the following research questions:

- Are true cognates more likely to be judged as known than non-true cognates?

- Will participants make more semantic errors in sentences with true cognates or non-true cognates? What types of semantic errors will be made, and which will be most common?

- Will participants make more syntactic errors in sentences with true cognates or non-true cognates? What types of syntactic errors will be made, and which will be most common?

By studying learner output across the semantic range of cognate types, quantitative and qualitative analyses were performed to determine which cognates created the greatest semantic and syntactic interference. This analysis was accomplished through a word knowledge scale, discrete translations, and a sentence writing activity. 


\section{Chapter Three: Methods}

The present study is a mixed-methods analysis of contextualized word knowledge of Japanese-English cognates via a sentence-writing task. I designed a word-knowledge scale and conducted quantitative and qualitative analyses. The quantitative portion consisted of coding participants' declarations of word knowledge, semantic errors of sentences, and syntactic errors of sentences. These coded data were then used to test for statistical significance via chi-squared analyses according to cognate status. The qualitative portion of the study consisted of analyzing semantic and syntactic error types in sentences, then grouping these errors according to emergent categories. What follows in this chapter is an account of all steps taken to recruit participants, select target words, create a precise survey instrument, analyze the data, and ensure reliability and validity.

\subsection{Participants}

The participants in this study were Japanese exchange students at a large university in the Pacific Northwest of the USA. Japanese students who choose to study at this university typically do so for at least one year. Data were collected during winter term, and these students had been living and studying in an American urban environment for approximately four-five months.

The exchange program between Japan and this university consists of two arms: A health/sustainability program and a business program. For admission into 
the health/sustainability program, students must have an internet-based TOEFL (iBT) score of at least 48 (out of 120), and an Institutional TOEFL (ITP)/Paper-based TOEFL (PBT) score of at least 460 (out of 677). The academic qualifications for the business program are more stringent. The business program requires an iBT score of 61, and an ITP/PBT score of 500. Based on these scores, the proficiency level of the participants for this study were intermediate (460-542) (Cambridge Institute, n.d.). During the winter term, there were eighteen Japanese students enrolled in the health/sustainability program, and four Japanese students enrolled in the business program. For this study, I was able to recruit a total of twenty participants, sixteen from health/sustainability, and four from the business program.

I recruited participants by contacting the university's specific JapaneseAmerican study abroad program. I met with an administrator to gain relevant student background information and discuss a tentative schedule. I then met with individual teachers to outline the study and prepare for the classroom visits. I wrote an email to students and they were made aware of the purpose of my visit. The survey was entirely voluntary, and consent forms were filled out by all participants (Appendix C). In exchange for their participation, students were entered into a raffle for a gift card to a local coffee shop.

\subsection{Target-word Selection}

Because this study was an analysis of word knowledge, the first necessary step was choosing words. According to Nation (2013), thirty lexical items 
constitute a strong sample; thus, thirty words were chosen for the instrument. These vocabulary words fell into two equal categories: true cognates and non-true cognates. These words were the result of brainstorming sessions between two Japanese informants and me. Both informants were Japanese citizens. One was a graduate student in applied linguistics who had lived in the US for twenty-four years; the other was a Japanese exchange student pursuing a post-baccalaureate business degree. The former (primary informant) assisted me with more linguistic issues. The latter informant assisted me more with current usages of vocabulary in Japan, as she had lived in Japan more recently, and many loanwords tend to be nonce and ephemeral (Daulton, 2008). Ideas for words were initially based on my own L2 Japanese intuitions (I had recently moved back to the US after living in Tokyo for five years), then verified for meaning and behavior by the two informants. There were roughly fifty words at the beginning of the word selection phase and these were eventually whittled down to thirty. Words that made it into the final survey instrument were based on four criteria, ranked here in order of importance: 1. semantic properties; 2 . word class; 3 . verb-collocational behavior; and 4. frequency.

I will first highlight the primary criterion - semantic properties. True cognates needed to be words that had a 1:1 semantic relationship in both languages. If a learner knows the meaning of the word in their L1, they should also know the meaning in L2 (Nation, 2001). For true cognates, the semantic selection process was relatively straightforward. The words for this category were taken from 
Daulton's (2008) Academic Borrowed Words List. This is a list composed of English to Japanese loanwords, which can also be found on the Academic Word List (AWL) (Daulton, 2008). As mentioned in Chapter 2, academic cognates share a high degree of semantic similarity (Daulton, 2008). This phenomenon is due to international standards for technical and scientific terms. Data (データ/deeta) and response (レス ポンス/resuponsu) for example, have the same meanings in Japanese as they do in English.

For semantics of non-true cognates, the selection process was more complex. Non-true cognates needed to be words that differed in meaning in some way between English and Japanese. Recall from Chapter 2 that Uchida (as cited in Daulton, 2008) proposed a taxonomy of six categories of cognates between English and Japanese. Five of these categories consist of words whose meaning has changed in some way (non-true cognates). Convergent cognates, divergent cognates, distant false friends, wasei-eigo, and close false friends are all non-true cognates. For the instrument of this study, three of these categories were collapsed into one single category of non-true cognates. (Figure 1). 
Cognate Types Proposed by Uchida (as cited in Daulton, 2008)

\begin{tabular}{|l|l|l|l|l|l|}
\hline $\begin{array}{l}\text { True } \\
\text { Cognates }\end{array}$ & $\begin{array}{l}\text { Convergent } \\
\text { Cognates }\end{array}$ & $\begin{array}{l}\text { Divergent } \\
\text { Cognates }\end{array}$ & $\begin{array}{l}\text { Distant False } \\
\text { Friends }\end{array}$ & $\begin{array}{l}\text { Wasei- } \\
\text { Eigo }\end{array}$ & $\begin{array}{l}\text { Close False } \\
\text { Friends }\end{array}$ \\
\hline
\end{tabular}

Figure 1. Collapsed categories of loanwords for the present study. Divergent Cognates, Distant False Friends, and Close False Friends all composed the Nontrue Cognate word category.

Wasei-eigo words and convergent cognates were excluded, as this was a study of English vocabulary. Because wasei-eigo are coinages that are created in Japan, they have no English equivalents. Convergent cognates are multiple Japanese words that converge onto a single English word; and these words are not as semantically interesting for the present study. To illustrate, Japanese バイク / baiku has the single meaning of motorcycle, where the idea of bicycle is denoted by a separate word,自転車/jitensha. If a participant imposed the Japanese word meaning of baiku onto the English word bike, for example, the effects would not be noticeable. Positive lexical transfer could occur, as bike can also denote motorcycle in English. Due to the shared meaning of bike (motorcycle), between English and Japanese, it is likely that this convergent cognate would behave no differently than a 
true cognate in the present study. Thus, they were excluded from the non-true cognate category.

Conversely, I was more interested in negative transfer. Because divergent cognates have taken on new meanings in Japanese, these are the words that are most likely to lead to semantic misunderstandings when acquiring English vocabulary. This can be illustrated with the non-true cognate パート/paato (part). Though the Japanese and English words share the meaning of section/element, the Japanese word paato and the English word part each have additional definitions within those languages. In English, part can also denote the nouns a role in a play, and the line where the hair is parted. In Japanese, paato is also a back-clipping of the English part-time job, which makes it a distant false friend, "distant or totally unconnected" (Daulton, 2008, p. 89) from its English source word. If a learner imposed the Japanese meaning of part-time job onto its English counterpart, this would be evidence of negative transfer. For this reason, only words that could lead to L1 semantic interference (negative transfer) were chosen for the non-true cognate word sample.

I wanted an accurate representation of the non-true cognate types, so I collected an even cross-section of the three: divergent cognates, distant false friends, and close false friends. Distant false friends were generally simple to choose. These items have one and only one primary definition in Japanese, and those definitions are quite different from their English counterparts. Classifying the other two non-true cognates - close false friends and divergent cognates, was less 
straightforward. Because most words have multiple definitions, it was more difficult to classify pure close false friends and pure divergent cognates for the categories in the study. For this reason, there was often overlap between all three types of nontrue cognates. Japanese ハンドル/handoru, for example, diverges into separate English terms - handle and steering wheel. Therefore it is a divergent cognate. The steering wheel meaning in Japanese is a close false friend, meanings that are "clearly different but close to one another" (Daulton, 2008, p. 89). Due to the overlap, the non-true cognate target word handle was sub-categorized as an ad hoc category of Divergent cognate including a close false friend. Table 2 below displays the subcategorizations of all fifteen non-true cognates.

Table 2

Sub-categorizations of Non-true Cognate Target Words

\begin{tabular}{ccc}
\hline Distant false friend & $\begin{array}{c}\text { Divergent cognate } \\
\text { including a distant false } \\
\text { friend }\end{array}$ & $\begin{array}{c}\text { Divergent cognate } \\
\text { including a close false } \\
\text { friend }\end{array}$ \\
Claim & Part & Fight \\
Demo & Post & Handle \\
Follow & Smart \\
Living & Tensionge \\
Mansion & Note & Sign \\
& Service & \\
\hline
\end{tabular}


The second criterion for word selection was lexical word class. As $90 \%$ of loanwords are nouns (Daulton, 2008), this word class constituted the bulk of all target words. For validity, both word lists of true and non-true cognates were evenly matched with eleven nouns, three verbs, and one adjective (Table 3). In Japanese, all of the lexical items are nouns, except for the two adjectives (one from each word list): true cognate, creative /クリエーティブ (kurieetebu), and non-true cognate smart /スマート(sumaato), which are both -na adjectives in the participants' L1. Thus, validity was increased due to the matching of lexical word classes across both target word lists (true and non-true cognates) in English and in Japanese.

Table 3

Lexical Word Classes of All Target Words

\begin{tabular}{|c|c|c|c|c|c|}
\hline \multicolumn{2}{|c|}{ Nouns } & \multicolumn{2}{|c|}{ Verbs } & \multicolumn{2}{|c|}{ Adjectives } \\
\hline True & Non-true & True & Non-true & True & Non-true \\
\hline Access & Claim & Illustrate & Fight & Creative & Smart \\
\hline Category & Demo & Link & Follow & & \\
\hline Challenge & Handle & Select & Living & & \\
\hline Code & Mansion & & & & \\
\hline Communication & Note & & & & \\
\hline Data & Part & & & & \\
\hline Design & Post & & & & \\
\hline Factor & Revenge & & & & \\
\hline Impact & Sign & & & & \\
\hline Response & Service & & & & \\
\hline Variation & Tension & & & & \\
\hline
\end{tabular}


It should be noted that many of these examples could be ambiguous in terms of word class. Access, for example, could be both a noun and a verb. Similarly, link could be both a verb and a noun. To mitigate any potential variance among the participants, every word was labeled on the survey according to part of speech, such as:

Target word: Access (n.)

Target word: $\operatorname{Link}(v$.)

The intention of this labeling was to have participants use the target word according to a specific word class, thus maintaining word-class consistency among all students, and across both word lists. The word class designations chosen for the survey words were based on their designations on the Academic Vocabulary List (AVL) (for true cognates) and the British National Corpus (BNC) (for non-true cognates).

One limitation to this study was the way in which participants responded to the word class distinctions. There were often cases where participants did not use the word according to the word class as it was labeled. The example below provides an illustration from the data with a true cognate:

Target word: Access (n.)

Participant's sentence: You need to access this page. Here, although the target word was labeled as a noun, the participant used it as a verb. I first struggled with the question of whether to throw such data out or to 
analyze them. I eventually made the decision to analyze the word according to the terms of the participants' usage. Thus, the sentence above was counted as correct. Knowing a word in any word-class manifestation was still evidence of knowing a word. Because I was looking at word knowledge, and not ability to follow instructions, all of these instances were counted as correct and remained in the data. The third criterion for selection was Japanese verb-collocational behavior of the target words. This decision was made based on Masson's (2013) analysis, which showed that a major cause of syntactic errors in English was the way cognates were collocated with verbs in Japanese. To that end, I chose enough words that may have led to these same error types noticed by Masson. I chose words that are collocated with broad Japanese verbs, such as する/suru (to do) and とる/toru (to take). These two verbs are responsible for various inconsistencies when it comes to translating words in context. The Japanese verb suru can mean English do (homework), take (a trip), make (a phone call), and even play (sports) (Ozaki, 2011). Toru can also take on awkward English translations when it engages with nouns, such as コミュニケーションする/komyunekeeshon toru, or take communication. Since these types of collocations yielded significant syntactic errors in previous research, it was imperative that they were chosen for the present study. Collocational behavior of these words in Japanese were verified by the two native Japanesespeaking informants.

Beyond verb-collocational behavior, the analysis of this study also remained open to the possibility of other syntactic errors. For this reason, only approximately 
half of each word list was composed of cognates that were collocated with suru or toru in Japanese, and half that were not. On the final word list, eight out of fifteen true cognates and seven out of fifteen non-true cognates were collocated with these verbs in Japanese (Table 4).

\section{Table 4}

Verb-Collocational Status in Japanese

\begin{tabular}{|c|c|c|c|}
\hline True & $\begin{array}{l}\text { Collocated with } \\
\text { suru/toru } \\
\text { in Japanese? }\end{array}$ & Non-true & $\begin{array}{c}\text { Collocated with } \\
\text { suru/toru } \\
\text { in Japanese? }\end{array}$ \\
\hline Access & $\checkmark$ & Claim & $\checkmark$ \\
\hline Category & & Demo & $\checkmark$ \\
\hline Challenge & $\checkmark$ & Fight & \\
\hline Code & & Follow & $\checkmark$ \\
\hline Communication & $\checkmark$ & Handle & \\
\hline Creative & & Living & \\
\hline Data & $\checkmark$ & Mansion & \\
\hline Design & $\checkmark$ & Note & \\
\hline Factor & & Part & \\
\hline Illustrate & & Post & \\
\hline Impact & & Revenge & $\checkmark$ \\
\hline Link & $\checkmark$ & Sign & $\checkmark$ \\
\hline Response & $\checkmark$ & Service & $\checkmark$ \\
\hline Select & $\checkmark$ & Smart & \\
\hline Variation & & Tension & $\checkmark$ \\
\hline
\end{tabular}

${ }^{a}$ suru/toru are broad Japanese verbs with meanings as various as do, take, take on, have, give, make, play, etc. 
The final criterion for target-word selection was frequency. At this stage, only a few words needed to be eliminated towards settling on the final thirty words. Once the criteria of semantics, word class, and collocational behavior were met, remaining items were then located on frequency lists. While there were roughly fifty words at the beginning of target word selection, there were now between thirty-five and forty. At this stage, I whittled down the list to the words that were as high frequency as possible. It was necessary for participants to be familiar with most words, so that they would be able to construct semantically appropriate sentences. True cognates were chosen according to their frequency on both the Academic Word List (AWL) (Daulton, 2008) and Academic Vocabulary List (AVL) (Gardner \& Davies, 2014). Non-true cognates were chosen according to their frequency on both the General Service List (GSL) (Bauman, n.d.) and the British National Corpus (BNC) (British National Corpus, n.d.). I cross-referenced potential true cognates between the AWL and AVL, and potential non-true cognates between the BNC and GSL. While the AWL and BNC only provide groupings of words according to sub-lists (of 60 words and 1000 words respectively), the GSL and AVL provides precise frequency counts for each word. The true cognate design (n.), for example, has an AVL frequency ranking of 127 , and appears in the $2^{\text {nd }}$ sub-list on the Academic Word List, which means it occurs somewhere between the $61^{\text {st }}$ and $120^{\text {th }}$ most common academic words. The words that occurred the most frequently across both lists were then chosen for the final fifteen words on both the cognate and non-true cognate lists. 


\subsection{Instrument}

Each survey contained thirty words; it was eleven pages long, with three words on each page. Three versions of the survey were created in order to mitigate the effects of test-taking fatigue. Words were randomized and assorted in various orders between all three versions of the test. Word order was the only difference among the three test versions. The front page of each survey was a title page, consisting of instructions and a task example (Appendix A). These instructions were in Japanese (Appendix B), with the task example in English (the same language that participants would be using). Because instructions were in Japanese, I felt confident that participants would not have any misunderstandings in how to proceed with the survey.

The questions on the survey were adapted from Masson's (2013) instrument and Paribakht and Wesche's (1993) Vocabulary Knowledge Scale (VKS). As mentioned in Chapter 2, the survey questions of Masson's study were as follows:

(1) I don't know this word

(2) I've seen this word and I know one meaning

(3) I know more than one meaning of this word and I can write a sentence using this word (2013)

The questions of the present study differed from the above questions in three key ways. First, participants here did not have to write a sentence if they declared that they did not know the meaning of the word (which was left unclear in Masson's study). Second, participants were not asked to declare knowledge of more than one 
meaning (Answer 3). I made this decision because knowing multiple definitions of a word was often irrelevant - some of the target words for this study have just one primary definition in English (i.e. category, variation, revenge, follow). If a participant could state that they knew just one definition of a word, this was sufficient. Third, instead of collapsing receptive and productive knowledge into one question for Answer (3), the present study had participants provide two productive declarations (a discrete translation of the word + a sentence), which could be used to provide fuller context of word knowledge. Key differences between Masson's word knowledge scale and my own are summarized in Table 5 below. 
Table 5

Differences in Word Knowledge Scale from Masson's (2013) to Present Study Masson (2013) The Present Study

1. It is unclear whether participants had to write sentences for words that they declared:

Answer (1) I don't know this word

and

Answer (2) I've seen this word and I know one meaning

2. Participants had to choose between:

Answer (2) I've seen this word and I know one meaning

and

Answer (3) I know more than one meaning of this word...

3. Participants had to declare receptive and productive knowledge in the same question:

Answer (3) I know more than one meaning of this word and can use it in a sentence.
1. Participants only had to write sentences for words that they declared:

Answer (3) I have seen this word before, and I think it means (synonym or translation).
2. Participants did not have to choose between knowing one meaning and knowing more than one meaning. Knowing one meaning was sufficient.

Answer (3) I have seen this word before, and I think it means (synonym or translation).

3. Participants' declared two types of productive knowledge (discrete translation + a sentence).

Answer (3) I have seen this word before, and I think it means (synonym or translation).

Sentence: 
I also adapted the survey questions from Paribakht and Wesche's (1993) Vocabulary Knowledge Scale (VKS), which appeared as follows:

I. I have never seen this word.

II. I have seen this word before, but don't know what it means.

III. I have seen this word before, and I think it means (synonym or translation)

IV. I know this word. It means . (synonym or translation)

V. I can use this word in a sentence:

Where the VKS consisted of a total of five questions, the present study collapsed these into three questions. Answer IV from the VKS was eliminated to prevent Japanese leaners from having to make such a bald, on-record declaration of "I know." Japanese students come from a culture that emphasizes humility and an educational environment that prioritizes careful consideration over hasty statements (Thompson, 2001). Thus, students may have reservations about choosing "I know" over "I think." For that reason, I think this word means was the most positive declaration of word knowledge that a participant could make in the present study.

I also changed a feature from Paribakht and Wesche's (1993) VKS with respect to the sentence-writing question. Instead of separating answers III and V, 
these two questions were merged. Participants were asked to write a sentence in conjunction with a synonym or translation. I made this change because I wanted to compare semantic and syntactic output. The discrete translations were necessary in order to provide the fullest picture of learners' knowledge of word meaning. In addition, having participants select a single answer choice instead of multiple answers added to the straightforwardness of the survey. There was less chance that participants would have been confused in the assessment procedures. With all of these changes in mind, the finalized survey questions of the present study (translated here into English) appeared as follows:

Target word: claim (n.)

1. I have never seen this word.

2. I have seen this word before, but I don't know what it means.

3. I have seen this word before, and I think it means (synonym or translation)

Sentence:

In the instructions section of the title page, participants were explicitly guided to write "mastery sentences," adopted from Masson (2012). Mastery sentences were 
meant to demonstrate a full semantic understanding of the word. For a sentence to be considered a mastery sentence and counted as correct, target words had to be contextualized in a way that showcased the target word's meaning, and could only be replaced by a close synonym. To clearly enforce this point, two example sentences were provided on the title page. One sentence clearly showcased the meaning of the target word; the other sentence demonstrated an ambiguous meaning (Appendix A). Both examples were accompanied by Japanese explanations of their linguistic differences. The mastery sentence example with the ad hoc target word contract was:

When I signed the contract, I became the owner of the house. The sentence which demonstrated an ambiguous meaning was:

I like contracts.

The former example, the mastery sentence, clearly demonstrates the meaning of the word. Contract can only be replaced by a close synonym-pact, arrangement, pledge, or a similar word. In the latter ambiguous example, there are a limitless number of noun phrases that could be substituted for the target word- i.e. I like cheese; I like science; I like soccer. The target word cannot only be replaced by a synonym; it is ambiguous, and therefore it is a clear demonstration of a poor example. 


\subsection{Procedures}

I visited two separate classrooms on two separate days to administer the study. My visits had been previously arranged, and the Japanese students knew they would be participating in an educational study. Participants filled out consent forms (Appendix C), and we began. The survey was written entirely in Japanese, except for the example, the target words, and their parts of speech, which were written in English. I provided oral English instructions for the participants. Participants were also encouraged to ask any clarification questions before or during the survey, and a native Japanese speaker was on hand to assist with any possible clarifications in L1. The survey took about 30 minutes.

\subsection{Analysis}

The survey responses were analyzed quantitatively and qualitatively. The quantitative analysis involved four steps: Recording participants' translations and synonyms from Answer (3); coding sentences for semantic accuracy; coding sentences for syntactic accuracy; and running chi-square frequency counts on coded data to determine the number of errors per cognate status. The qualitative analysis involved two steps: analyzing sentences for semantic and syntactic error trends, and aggregating these trends per cognate status.

The first step in coding the data was to look at what participants wrote for the non-sentence writing portion of Answer (3) — the Japanese synonyms and 
English translations. By having participants record decontextualized translations and synonyms, these words were able to serve as a semantic backup in the event that a participant wrote an ambiguous sentence. If a sentence were ambiguous (i.e. Access is important), I could then look back at the synonyms and translations. If the participant provided a correct synonym or translation (Access: 手段/shuudan (way; means; measure)), then the sentence was coded as correct. Thus, even when participants failed to write clear enough mastery sentences, I was nevertheless able to evaluate the semantics of the sentence according to the meaning that participants had declared through the discrete declaration.

The next steps were to evaluate the semantic and syntactic accuracy of the sentences. The coding scheme for sentence semantics consisted of three possible answers. Sentences were graded as semantically accurate, semantically inaccurate, or were thrown out due to no sentence being written. I read each sentence, evaluated it in terms of meaning, consulted the translations and synonyms when necessary to verify semantic understanding, and assigned a score of either correct or incorrect. For procedures on how inter-rater reliability was achieved, refer to Section 3.6 Reliabilty and Validity.

If sentences were correct semantically, I was then able to evaluate their syntax. I did not want to code for syntax if a participant clearly did not know the meaning of the word. Thus, only sentences that were semantically correct were eligible to be evaluated for their syntax. The target word living illustrates this point below. 
Participant X's sentence: My family is gathered in our living.

Participant Y's sentence: I'm living in Tokyo.

In Japanese, リビング/ribingu (living) is a back-clipping of the English term living room. Because Participant X has clearly imposed the Japanese meaning onto the English meaning, the analysis for this sentence would stop here. Syntactic analyses were only conducted on sentences that displayed correct semantic word knowledge. Because Participant Y's sentence is semantically correct in English, the sentence was then eligible to be evaluated for syntax. A flow chart of this methodological process is provided in Figure 2 below. 
3. I have seen this word before, and I think it means (synonym or translation)

\section{Sentence:}

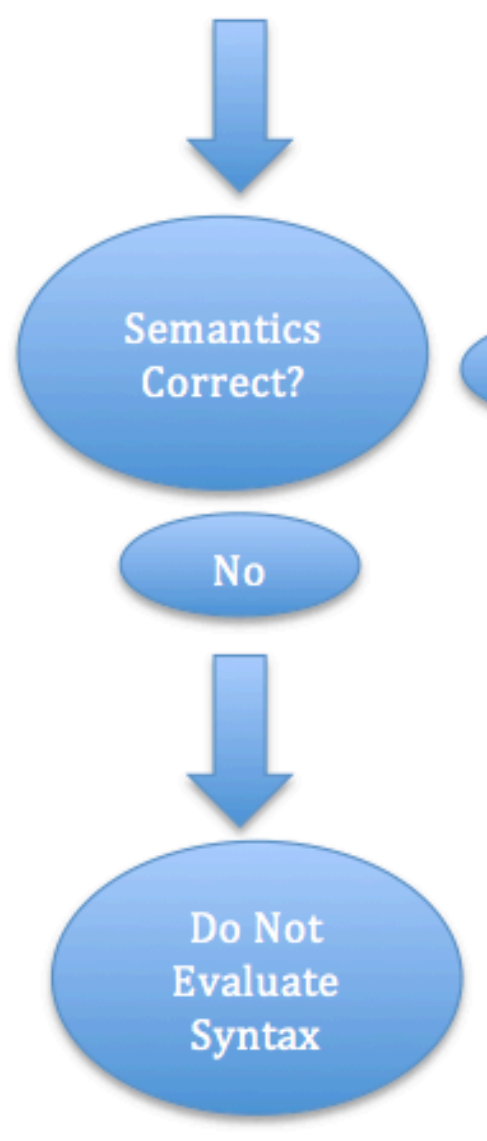

Figure 2. Process for analysis of responses for Answer (3) of the word knowledge scale. Only sentences that were evaluated correctly for semantics were eligible to be evaluated for their syntax. 
This decision was made to ensure that a syntactic judgment was made if and only if participants demonstrated correct knowledge of word meaning. Without this step, it would have been possible to misevaluate target words that appeared in a syntactically appropriate environment by chance, or via morphological guesswork by participants. Coding these types of sentences would result in an inaccurate representation of the participants' word knowledge.

The coding scheme for syntax was strictly binary: correct or incorrect. No data were thrown out because they were all based on semantically correct sentences. Syntactic scores were measured based on the grammar around the target word only. If a sentence contained a syntactic error that was independent of the target word, then the sentence was still coded as correct. The analysis of this study focused on the syntactic frame of target words, not syntactic errors in general. To illustrate with the target word variation, if a sentence read: Every people has variations of preference, this output was still coded as correct. The syntactic error here lies close to the target word, but is influenced by a separate grammatical problem. The problematic verb choice has fails to meet correct subject-verb agreement with people, but is not influenced by the target word, variation. The grammatical problem could also be diagnosed as improper choice of the subject people. Perhaps everybody would have been a better choice. Yet this error is still unrelated to the target word, and would not count in the evaluation of syntactic accuracy. 
The sentence above also contains a grayish area with respect to the preposition of, in the phrase variations of preference. A native speaker of English might be more inclined to say variations in preference. For cases like this, when I had doubts, I consulted a corpus. Specifically, The Corpus of Contemporary American English (COCA): 520 million words, 1990-present (Davies, 2008) was used as a guide. Strings of words were searched as collocations. For the example above, variations and of were collocated 832 times. Variations and in were collocated 2117 times. Though variations in greatly outnumbers variations of, there were nonetheless enough examples in the corpus of variations of to bolster reliability for that collocation. Thus, these types of variations were only recorded as incorrect when there were dramatic differences and very few examples of questionable phrasing. To sum, despite the ostensible awkwardness of the participant's sentence, Every people has variations in preference, items like this were still coded as correct based on the aforementioned set of principled decisions.

After coding the survey answers, and semantic and syntactic evaluations of sentences, all the data were entered into SPSS and chi square frequency counts were calculated. Three separate counts were run that accounted for: 1. participants' judgment of word knowledge between true and non-true cognates (Answers 1, 2, or 3 on the survey); 2 . semantic accuracy in the sentences between true and non-true cognates; and 3. syntactic accuracy in the sentences between true and non-true cognates. 
For the qualitative analysis of sentence semantics, incorrect word meanings in context were analyzed and grouped according to semantic problem. As negative transfer was a predicted category, I was particularly watchful for these types of errors. All other potential categories remained exploratory, and were allowed to emerge from the data. I then counted total error types and grouped them in order of importance. This was done for total target words, as well as per cognate status.

For the qualitative analysis of syntax, error types were recorded each time a sentence contained an error in the syntactic frame of a target word. Based on previous research (Masson, 2013), I was watchful for verb-collocational difficulties by remaining vigilant of unnatural pairings between English verbs and target words. As this portion of the study was exploratory, I also remained open to other error types. As with semantic determinations, the data were allowed to emerge based on my grammatical judgments. Some grammatical problems overlapped and I was forced to make a series of principled decisions regarding which types of errors constituted which types of categories (See Results- Section 4.5/Table 12). I then counted total error types and grouped them in order of importance. Grouping was done for total target words, as well as according to cognate status.

\subsection{Reliability and Validity}

Before the final analysis, I achieved inter-rater reliability with my primary Japanese informant (the graduate student in applied linguistics). I selected $20 \%$ of the data for the two of us to code separately. Because there were thirty target 
words, $20 \%$ of the data yielded all participants' synonyms, translations, and sentences for six words. A natural split for this six-word sub-section of data was three true cognates and three non-true cognates. I analyzed the data first, then passed it on to the other grader. The six words I chose for us to practice with had yielded a range of scores from my own a priori analysis. There were words that had many correct semantic scores with many correct syntactic scores; words that had many correct semantic scores with many incorrect syntactic scores; and words that had many incorrect semantic scores with some correct syntactic scores. Accounting for eighteen sentences that were left blank, among twenty participants, this sixword subset of data consisted of 102 sentences. The Japanese rater graded each item according to my coding scheme, which had been explained in detail, and practiced with feedback. We achieved reliable numbers with $99.4 \%$ agreement for semantics and $96.1 \%$ agreement for syntax. Once the coding scheme was verified from the other grader, I proceeded with additional rounds of coding for the remaining 480 sentences.

Overall, the design of the study was scrupulous and exhaustive. For validity, target words were chosen carefully according to semantic properties, lexical word class, collocational behavior, and frequency. These four factors were closely matched across both word lists of true and non-true cognates. The survey instrument's word knowledge scale was adapted from two previous studies, then modified for precision, relevance, and cultural sensitivity. Three separate randomized versions of the survey were administered to control for test-taking 
fatigue. Evaluations of participants' borderline productions were informed by a corpus, and a second grader was used to achieve inter-rater reliability. Final results were tested for statistical significance across cognate types, another key difference from Masson's (2013) analysis, where no statistics were utilized (Masson, personal communication, December 8, 2015). 


\section{Chapter Four: Results}

This chapter will provide results of the three research questions that were analyzed quantitatively and the two research questions that were analyzed qualitatively. In the quantitative portion, I will provide tables with raw error counts and percentages for totals and per cognate status. Chi squared results for statistical significance are also included. In the qualitative portion, I will also provide tables of the semantic and syntactic error categories that emerged for totals and per cognate status.

\subsection{Quantitative Results of Word Knowledge}

With respect to the first quantitative research question, are true cognates more likely to be judged as known than non-true cognates?, participants were more likely to declare that they knew the meaning of true cognates. Table 6 shows that for Answer (1) I have never seen this word before, there were zero instances for true cognates, and five instances for non-true cognates. These non-true cognates were: demo (2x), living (1x), and mansion (2x). As the word knowledge continuum became more affirmative, Answer (2) I have seen this word before but do not know what it means, yielded twenty-four instances for true cognates, and thirty-nine instances for non-true cognates. And when it came to the most affirmative declaration of word knowledge, Answer (3) I have seen this word before and can provide an English synonym or Japanese translation, there were 276 instances for true cognates, and 256 instances for non-true cognates. Thus, as a percentage, participants made the 
most positive declaration of word knowledge $92 \%$ of the time with true cognates, versus $85.3 \%$ of the time with non-true cognates, and there was a statistically significant difference between participants' declaration of word knowledge and cognate status $\chi 2(2)=9.323, \mathrm{p}<.05$.

Table 6

Participants' Declaration of Word Knowledge per Cognate Status

\begin{tabular}{|c|c|c|c|c|}
\hline & $\begin{array}{l}\text { I have never } \\
\text { seen this word } \\
\text { before. }\end{array}$ & $\begin{array}{l}\text { I have seen } \\
\text { this word } \\
\text { before but do } \\
\text { not know } \\
\text { what it } \\
\text { means. }\end{array}$ & $\begin{array}{l}\text { I have seen this } \\
\text { word before and } \\
\text { can provide an } \\
\text { English synonym } \\
\text { or Japanese } \\
\text { translation }\end{array}$ & Total \\
\hline True cognate & $0(0 \%)^{\mathrm{a}}$ & $24(8.0 \%)$ & $276(92.0 \%)$ & 300 \\
\hline $\begin{array}{l}\text { Non-true } \\
\text { cognate }\end{array}$ & $5(1.7 \%)$ & $39(13.0 \%)$ & $256(85.3 \%)$ & 300 \\
\hline Total & $5(0.8 \%)^{b}$ & $63(10.5 \%)$ & $532(88.7 \%)$ & 600 \\
\hline
\end{tabular}




\subsection{Quantitative Results of Sentence Semantics}

With respect to the second quantitative research question, do participants make more semantic errors with non-true cognates?, participants were more likely to make semantic errors with non-true cognates than with true cognates. Table 7 shows that participants were more likely to make semantic errors in sentences with non-true cognates than with true cognates. There were thirty-one instances of participants choosing not to write a sentence with true cognates, and forty-seven instances for non-true cognates. When participants wrote sentences, for true cognates, there were eleven instances of incorrect semantic usage and 258 instances of correct semantic usage. For non-true cognates, there were sixty-six instances of incorrect semantic usage and 187 instances of correct semantic usage. When viewed as a percentage, the results for semantic usage for non-true cognates reveal the least accurate answers across all metrics analyzed in this entire study. Participants were only able to use non-true cognates in semantically accurate ways $62.3 \%$ of the time. In contrast, participants were able to use true cognates in semantically accurate ways $86 \%$ of the time. Thus there was a statistically significant relationship between semantic errors and cognate status $\chi^{2}(2)=53.896, p<.05$. 
Table 7

Semantic Evaluation of Participants' Sentences per Cognate Status

No sentence Incorrect Correct Total written

\begin{tabular}{|c|c|c|c|c|}
\hline True cognate & $31(10.3 \%)^{*}$ & $11(3.7 \%)$ & $258(86.0 \%)$ & 300 \\
\hline Non-true & $47(15.7 \%)$ & $66(22.0 \%)$ & $187(62.3 \%)$ & 300 \\
\hline & $78(13.0 \%)^{* *}$ & 77 (12.8\%) & $445(74.2 \%)$ & 600 \\
\hline Total & & & & \\
\hline
\end{tabular}

\subsection{Quantitative Results of Sentence Syntax}

With respect to the third quantitative research question, do participants make more syntactic errors with true cognates?, there was no observable relationship between the frequency of syntactic errors and cognate status. Because participants wrote more semantically accurate sentences for true cognates, there were a total of 258 sentences to judge for true cognates versus 187 sentences for non-true cognates. Table 8 shows that for true cognates, sentences were syntactically accurate $77.1 \%$ of the time. For non-true cognates, sentences were syntactically accurate $78.1 \%$ of the time. The accuracy percentage for non-true cognates was higher than true cognates, which is in line with Masson's (2013) findings, but the difference between the two cognate types was less than $1 \%$. Thus, 
no statistically significant relationship was observed between cognate status and syntactic accuracy $\chi^{2}(1)=.055, \mathrm{p}>.05$.

Table 8

Syntactic Evaluation of Participants' Sentences per Cognate Status

\begin{tabular}{|c|c|c|c|}
\hline & Incorrect & Correct & Total \\
\hline True cognate & 59 (22.9\%)a & 199 (77.1\%) & $258^{c}$ \\
\hline $\begin{array}{l}\text { Non-true } \\
\text { cognate }\end{array}$ & 41 (21.9\%) & 146 (78.1\%) & 187 \\
\hline Total & $100(22.5 \%)^{\mathrm{b}}$ & 345 (77.5\%) & 445 \\
\hline \multicolumn{4}{|c|}{$\begin{array}{l}\text { Note. } \chi^{2}=.055, \mathrm{df}=1, \mathrm{p}=.814(\mathrm{p}>.05) \\
\text { apercent per cognate type } \\
\text { bpercent of total sentences } \\
\text { cTotals are less than } 300 \text { because syntax of sentences was only evaluated from } \\
\text { semantically correct sentences. Note that totals here correspond to number of } \\
\text { correct sentences from Table } 7\end{array}$} \\
\hline
\end{tabular}

\subsection{Qualitative Results of Sentence Semantics}

The incorrect sentences were then analyzed qualitatively to determine if there were patterns of semantic errors. In this analysis, two main error types emerged: participants imposing the Japanese meaning onto the English meaning (negative transfer), and participants demonstrating word knowledge that was similar, but not identical to actual English usage. The first error type was only 
possible with non-true cognates. Because non-true cognates have Japanese meanings that differ from English meanings, there is potential for negative transfer, or interference, from L1 to L2. True cognates, on the other hand, share the same meanings across both languages; thus negative transfer from Japanese to English would be impossible. Examples of L1 interference with non-true cognates are displayed in Table 9.

\section{Table 9}

Examples of L1 interference in Participants' Sentences

\begin{tabular}{|c|c|c|}
\hline $\begin{array}{l}\text { Target word } \\
\text { (all true cognates) }\end{array}$ & Participants' sentence & $\begin{array}{l}\text { Explanation with } \\
\text { Japanese definition }\end{array}$ \\
\hline Claim & $\begin{array}{l}\text { *My mother claimed to the } \\
\text { restaurant because there } \\
\text { were insects in the dish. }\end{array}$ & $\begin{array}{l}\text { claim means complaint in } \\
\text { Japanese }\end{array}$ \\
\hline Demo & $\begin{array}{l}\text { *We tried to demo to } \\
\text { reduce the tax. }\end{array}$ & $\begin{array}{l}\text { demo means political } \\
\text { protest in Japanese }\end{array}$ \\
\hline Handle & $\begin{array}{l}\text { *I grasp a handle when I } \\
\text { drive. }\end{array}$ & $\begin{array}{l}\text { handle means steering } \\
\text { wheel in Japanese }\end{array}$ \\
\hline Post & $\begin{array}{l}\text { *I need to find posts to } \\
\text { send letters. }\end{array}$ & $\begin{array}{l}\text { post_means mailbox in } \\
\text { Japanese }\end{array}$ \\
\hline Sign & $\begin{array}{l}{ }^{*} \text { Can you make a sign on } \\
\text { your receipt? }\end{array}$ & $\begin{array}{l}\text { sign means signature in } \\
\text { Japanese }\end{array}$ \\
\hline
\end{tabular}


The second error category that emerged, meanings that were similar but not identical to English usage, was possible with both true and non-true cognates (Table 10). Here, L1 interference was not a contributing factor. Learners seemed to be generally aware of the meanings of these words (receptive knowledge), yet were just off the mark when it came to using these words in sentences (productive knowledge). 
Table 10

Examples of Slightly Incorrect Participant Sentences

Target word Participants' sentence Explanation of a similar, but not identical English meaning

Category

(true cognate)

(true cognate)

Revenge

(non-true cognate)

Service

(non-true cognate)
*I can cook anything in my category.

*My business part is international part.

*Japan has many revenges against other countries.
Category here was likely meant to mean genre, such as Thai or Mexican food, or baked goods. Usage was judged as unnatural.

Part could be interpreted as "division within a company," but was judged as overly ambiguous.

Revenge here was interpreted here as tensions, or historical conflict, rather than the more accurate English definition of "inflicting harm based on the wrongdoing of another."

Numerous other lexical choices would have been more fitting here, including: provides, displays, has. Service is also used transitively here, but that usage in English means to repair/fix, such as "servicing a car."

Numeric totals of all qualitatively analyzed semantic sentence errors from the two emergent categories for true and non-true cognates are displayed in Table 11 below. 


\section{Table 11}

Total Semantic Error Types per Cognate Status

\begin{tabular}{llll}
\hline & Negative transfer & $\begin{array}{l}\text { Slightly Incorrect } \\
\text { English meaning }\end{array}$ & Total \\
\hline True cognates & $0(0 \%)^{\mathrm{a}}$ & $11(100 \%)$ & 11 \\
Non-true cognates & $62(93.9 \%)$ & $4(6.1 \%)$ & 66 \\
Total & $62(80.5 \%)^{\mathrm{b}}$ & $15(19.5 \%)$ & 77 \\
\hline
\end{tabular}

apercent of cognate type

${ }^{b}$ percent of total

The difference between the participants' decontextualized usage versus contextualized usage is also important. It should also be noted that in many cases, the discrete translations or synonyms were often correct. For example, the participant who wrote *We need to challenge with nature also recorded 挑戦/ chousen, which translates directly to challenge in English. Given the incomprehensibility of the word in the sentence, however, this sample could not be graded as a correct mastery sentence. Thus, the participant failed to demonstrate correct semantically contextual knowledge of the target word. This phenomenon of recording accurate synonyms or translations in isolation, yet recording inaccurate representations of the word in context also occurred with true cognates code, factor, link, and non-true cognates demo, handle, part, and tension. 


\subsection{Qualitative Results of Sentence Syntax}

The sentences that demonstrated correct semantics but also contained syntactic errors were analyzed qualitatively for patterns. A total of eight grammatical-error categories emerged from this data. These were: collocations, pluralization, word form, countability, articles, subject-verb agreement, tense, and word order. I made principled decisions in the criteria for choosing each of these categories. The first category, collocations, is defined as a group of two or more words that frequently co-occur. (Shin \& Nation, 2007; Biber, Conrad, \& Leech, 2013). In the present study, sentences that displayed a lack of proper collocational usage were coded as collocational errors. This lack of proper usage was evidenced by participants using the wrong co-occurring word, using no co-occurring word, or overusing a word that does not co-occur with the target word (Table 12). In all cases, from a teacher's perspective, the learner has yet to acquire common strings of words, or chunks, around the target word. Thus, there is a gap in learned collocations within the student's interlanguage. The next error category, plurals, was caused by participants not pluralizing words that should be pluralized, e.g. We need to separate category. The next error category, word form, was caused by four distinct issues: participants using a nominal form over an adjectival form, using a nominal form over an verbal form, using a verbal form over a nominal form (Table 12), or using an incorrect superlative form, such as He is the most smart guy in the class. The next category, count errors were caused by participants counting uncountable nouns-Poor people don't have good accesses to health care, and article 
overusage with an uncountable noun - I need a data to write essay. Though an article was overused in this example, the article was not the primary issue.

Uncountable nouns are a unique type of noun, and mastering their usage supersedes an understanding of the way articles are used. The next category, article errors was caused only by missing articles, such as My dad died from impact to his head. In this case, and others like it, the participant failed to demonstrate correct knowledge of fundamental article usage (before accounting for specific noun types which do not take articles, such as uncountable nouns). The next category, subject-verb agreement, was caused by participants choosing the wrong verb form to pair with a plural noun, e.g. There is two factors why we have to study. The next category, errors of tense, was caused by a participant failing to use the correct version of a word that flouts the normal rules of tense, such as I fighted you yesterday because we had different opinions. Finally, word order errors were caused by transposing words within a sentence that should be located elsewhere, such as I posted link homepages, instead of I posted homepage links. In all cases, the error categories I chose were those that were the most front and center, and those that I would choose to address first in as a teaching context. Table 12 below is a taxonomy of all sub-categorizations of syntactic error categories, with examples. 
Table 12

Error Types that Comprised Each Syntactic Error Category

\begin{tabular}{|c|c|}
\hline $\begin{array}{l}\text { Error } \\
\text { Category }\end{array}$ & Description of Error Type with Example \\
\hline \multirow[t]{5}{*}{ Collocation } & Prepositional Overuse- ${ }^{*}$ I cannot access to my account. \\
\hline & Prepositional Choice- ${ }^{*}$ I have a few challenges about studying abroad. \\
\hline & Missing preposition - *I responded teacher question. \\
\hline & Verb choice- *I want to do the challenge without giving up. \\
\hline & Missing verb- ${ }^{*}$ He defeated me last time so I'd like to revenge next. \\
\hline Plural & Unpluralized- ${ }^{*}$ We need to separate category. \\
\hline Word Form & $\begin{array}{l}\text { Nominal should be adjectival- }{ }^{*} \text { The global climate change is a } \\
\text { challenge problem. }\end{array}$ \\
\hline
\end{tabular}

Nominal should be verbal- * He didn't have any response when I sent the email.

Verbal should be nominal— * He made fun of me but I didn't have a respond.

Incorrect superlative form- ${ }^{*}$ He is the most smart guy in the class.

Count Uncountable noun is counted- *Poor people don't have good accesses to health care.

Article overusage with uncountable noun- *I need a data to write essay.

Articles Missing article- $\quad *$ My dad died from impact to his head.

Subject- $\quad$ Singular verb should be plural- * There is two factors why we have to verb study.

Agreement

Word does not follow exception to the rule- * I fighted you yesterday Tense because we had different opinions.

Word Order Inversion- *I posted link homepages 
In coding the data, there were a few instances where it was not immediately clear how to properly code grammatically incorrect sentences. Thus, some sentences were coded for two error types, with .5 points going to each error category. I made this decision to ensure that the summed amount of each individual error category equaled the summed amount of total errors, and to not double count errors. For true cognates, there were two sentences that were doubly coded. The sentence, We have to find out factor that why we can't win was coded for both article and pluralization. A correct version of this sentence may be read as We have to find out the factor... (direct article inserted), or We have to find out factors... (pluralized). The sentence, The author illustrate the importance of the study was coded for both tense and subject-verb agreement. The past tense form of the verb illustrated would have been correct; or the singular-subject marked form of the verb illustrates would have also been counted as correct. For non-true cognates, one sentence was doubly coded: I always take note what a teacher says in class, which was coded for pluralization and collocation. A correct version of this sentence might be read as I always take notes... (pluralization), or I always take note of...(prepositional collocation).

There were two notable findings among these error categories. First, there was a large number of collocational errors, accounting for $38.5 \%$ of all error types across both cognate categories. Within each cognate category, $35.6 \%$ of syntactic errors were collocational for true cognates, and $42.7 \%$ were collocational for non- 
true cognates. Other common errors across both cognate categories included problems with pluralization, articles, and subject-verb agreement (Table 13). 
Table 13

Total Syntactic Error Types per Cognate Status

\begin{tabular}{|c|c|c|c|c|}
\hline $\begin{array}{l}\text { Grammatical- } \\
\text { error category }\end{array}$ & $\begin{array}{l}\text { Participants' } \\
\text { Examples }\end{array}$ & $\begin{array}{l}\text { True } \\
\text { Cognates }\end{array}$ & $\begin{array}{l}\text { Non-true } \\
\text { Cognates }\end{array}$ & Total \\
\hline Collocations & $\begin{array}{l}{ }^{*} \text { I cannot access } \\
\text { to my account. }\end{array}$ & $21(35.6 \%)^{\mathrm{a}}$ & $\begin{array}{l}17.5 \\
(42.7 \%)\end{array}$ & $\begin{array}{l}38.5 \\
(38.5 \%)^{b}\end{array}$ \\
\hline Pluralization & $\begin{array}{l}\text { *I'm taking note } \\
\text { in the class. }\end{array}$ & $\begin{array}{l}11.5 \\
(19.5 \%)\end{array}$ & $9.5(23.2 \%)$ & $21(21 \%)$ \\
\hline Word form & $\begin{array}{l}\text { *He is the most } \\
\text { smart guy in the } \\
\text { class. }\end{array}$ & $10(17 \%)$ & $1(2.4 \%)$ & $11(11 \%)$ \\
\hline Countability & $\begin{array}{l}\text { *These countries } \\
\text { still have a } \\
\text { tension because } \\
\text { of the past war. }\end{array}$ & $5(8.5 \%)$ & $8(19.5 \%)$ & $13(13 \%)$ \\
\hline Articles & $\begin{array}{l}\text { *I could get } \\
\text { response from } \\
\text { my teacher. }\end{array}$ & $6.5(11 \%)$ & $1(2.4 \%)$ & $7.5(7.5 \%)$ \\
\hline $\begin{array}{l}\text { Subject-verb } \\
\text { agreement }\end{array}$ & $\begin{array}{l}\text { *There are some } \\
\text { variation of ice } \\
\text { cream. }\end{array}$ & $3.5(5.9 \%)$ & $1(2.4 \%)$ & $4.5(4.5 \%)$ \\
\hline Tense & $\begin{array}{l}\text { *I fighted with } \\
\text { American guys, } \\
\text { but I lose. }\end{array}$ & $.5(.8 \%)$ & $3(7.3 \%)$ & $3.5(3.5 \%)$ \\
\hline Word order & $\begin{array}{l}\text { *I posted link } \\
\text { homepages. }\end{array}$ & $1(1.7 \%)$ & $0(0 \%)$ & $1(1 \%)$ \\
\hline Total & & 59 & 41 & 100 \\
\hline
\end{tabular}

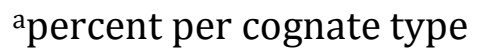
bercent of total 
The second notable finding on collocations was the type of collocational errors made within each cognate category. For true cognates, prepositionalcollocational errors were the most common, e.g. Sorry that I responded you so late. (missing preposition). Among true cognates, prepostional-collocational errors made up $66.7 \%$ of all collocational errors. These error types were followed by verbalcollocational errors, which made up $23.8 \%$ of all collocational error types (Table 14).

\section{Table 14}

\section{Sub-categorizations of Collocational Errors per Cognate Status}

\begin{tabular}{llll}
\hline $\begin{array}{l}\text { Collocational-error } \\
\text { Category }\end{array}$ & True Cognates & Non-true Cognates & Total \\
\hline $\begin{array}{l}\text { Prepositional- } \\
\text { collocational Error }\end{array}$ & $14(66.7 \%)^{\mathrm{a}}$ & $4.5(25.7 \%)$ & $18.5(48.1 \%)^{\mathrm{b}}$ \\
$\begin{array}{l}\text { Verbal- } \\
\text { collocational Error }\end{array}$ & $5(23.8 \%)$ & $12(68.6 \%)$ & $17(44.2 \%)$ \\
$\begin{array}{l}\text { Set-phrase } \\
\text { Collocational Error }\end{array}$ & $2(9.5 \%)$ & $1(5.7 \%)$ & $3(7.7 \%)$ \\
$\begin{array}{l}\text { Total Collocational } \\
\text { Errors }\end{array}$ & $21(54.5 \%)^{\mathrm{c}}$ & $17.5(45.5 \%)$ & $38.5(100 \%)$ \\
\hline
\end{tabular}

\footnotetext{
a Percent per cognate status

b Percent of total

c Percent of cognate status per both cognates
} 
The remaining $9.5 \%$ of collocational errors for true cognates was for the target word communication, and how it was paired with the word skill. These two sentences were, It is the most important to get the communication skill, and Communication skill is important. The grammatical judgment here may be dubious when the singular skill is compared with the plural skills. Because there were questions in my mind regarding this usage, I consulted COCA. The collocate search revealed 1005 usages of the plural communication skills versus just 19 usages of the singular communication skill. When the singular examples in COCA were analyzed, the usage generally referred to types of communication skills, such as humor, listening, and public speaking. The manner in which communication skill was used by the two participants seemed to represent the more general concept of general communication skills, thus they were marked as incorrect.

For non-true cognates, verbal-collocational errors were the most common, e.g. I want to do revenge to him (verb choice). Verbal-collocational errors made up $68.6 \%$ of all collocational errors for non-true cognates. Prepositional-collocational errors made up 25.7\%, and a single set phrase made up 5.7\% (Table 13). That set phrase use was adjectival - I can get a lot of service in this restaurant. This is not an utterance that a fluent English speaker would make. While one possible interpretation of this particpants' sentence could be I can get a lot of services in this restaurant, the more likely interpretation that the student meant is I can get good service in this restaurant. Good service is a frequent co-occurrence of an adjective and noun, thus it was counted as a set phrase collocation. 
The outliers of the three set phrase errors notwithstanding, the important finding here is the clear difference between the types of collocational errors used within each cognate type. Over two-thirds of collocational errors for true cognates were caused by prepositional-collocational issues (66.7\%), and over two-thirds of collocational errors for non-true cognates were caused by verbal-collocational issues (68.6\%). The implications of these findings for leaners are discussed in Chapter 5: Discussion and Conclusion.

Overall, collocations were by far the most problematic of all error types regardless of cognate status. Collocational errors (including verbal, prepositional, and set phrasal) were responsible for $38.5 \%$ of all syntactic errors across both cognate categories. This finding both supports, and runs counter to, Masson's (2013) findings. Collocations created the greatest difficulties for cognates in context (in line with Masson's findings), yet there was not a statistically significant difference in the number of errors per cognate status (counter to Masson's findings). The results of the present study also found that when collocational errors were analyzed per cognate status, true and non-true cognates each had their own specific sets of trends.

In summary of the results, the quantitative analysis of this study revealed three major findings:

- There was a statistically significant relationship between cognate status and word knowledge declaration. Participants were more likely to declare that they knew a true cognate than a non-true cognate. 
- There was a statistically significant relationship between cognate status and semantic accuracy in sentences. Participants were more likely to write a semantically accurate sentence with a true cognate than a non-true cognate.

- There was no statistically significant relationship between cognate status and syntactic accuracy. Participants were not more likely to write a syntactically accurate sentence with a true cognate than a non-true cognate.

The qualitative analysis revealed the following:

- There were two major error categories that contributed to semantic inaccuracies:

- negative transfer, which was responsible for the bulk of non-true cognate errors, and

○ usages that were similar, but slightly incorrect to English usage, which was responsible for $100 \%$ of true cognate errors

- There were eight grammatical categories that contributed to syntactic inaccuracies. Collocational difficulties constituted the greatest challenge for participants across both cognates types.

- Of these collocational issues, prepositional collocations (missing preposition, prepositional choice, and prepositional overuse) were responsible for the majority of true cognate syntactic errors, while verbal collocations (missing verb or verb choice) were responsible for the majority of non-true cognate syntactic errors. 


\section{Chapter Five: Discussion and Conclusion}

The results of this study indicate important differences in the ways that true and non-true cognates are understood by Japanese learners of English. Participants were more likely to declare that they knew the meaning of a true cognate versus a non-true cognate. There was a statistically significant difference in semantic knowledge between true and non-true cognates. And there was no statistically significant difference in participants' syntactic output between true and non-true cognates. The difference in semantic knowledge was most often caused by negative transfer for non-true cognates, and "slightly incorrect" usages were always responsible for incorrect usage of true cognates. The qualitative analysis of sentence syntax revealed that collocations were by far the most common error types across both types of cognates. Of these collocations, prepositional collocational errors were most often responsible for true cognate syntactic errors, and verbal collocational errors were most often responsible for non-true cognate errors.

The results contained in this study can provide educators and researchers with a fuller context from which to launch their vocabulary curricula, specifically those pertaining to Japanese-English word pairs. As I have outlined, there is an abundance of research pointing to the learning support provided by cognacy (Bultena, Dijkstra and van Hell, 2014, Daulton, 2008; Kelley and Kohnert 2012; Montelongo \& Hernandez, 2013; Nation, 2001). Yet, much of this research has been ignored by educators and curriculum designers, especially for Japanese learners of English. The failure to tap into this potentially useful "built-in lexicon" is due to the 
dubious reputation of cognates among educators, and the issue not being fully understood (Daulton, 2008). To address this gap, I conducted a thorough analysis of semantic and syntactic usage between high-frequency true and non-true cognates. The present research has built on the recent findings of Rogers, Webb, and Nakata (2014), and Masson (2013) to test claims of the syntactic interference of true cognates and non-true cognates, and to unearth any previously undiscovered findings surrounding the way cognates are used in context.

\subsection{Discussion of Findings per Research Question}

In answering the first research question pertaining to which cognate type would be more likely to be judged as known, it was found that participants were more likely to judge a true cognate as known than a non-true cognate. When participants saw a word that was a true cognate, they were more likely to declare that they knew that word. When the word was a non-true cognate, participants did not make as many positive declarations. Because there were zero instances of participants reporting I have never seen this word before for true cognates, this tells us that learners were generally more familiar with these items than non-true cognates.

The five instances of I have never seen this word before for non-true cognates were demo (2x), living (1x), and mansion (2x). Living, which in Japanese is リビング /ribing $u_{\llcorner}$a back-clipping of the English living room, stands apart from demo and mansion for two reasons: it is the most phonetically dissimilar from its Japanese 
equivalent (substituting individual segments $/ \mathrm{l} /$ for $/ \mathrm{r} /$ and $/ \mathrm{v} /$ for $/ \mathrm{b} /$ ), and it is an inflectional form of the English base verb live. It is possible that this participant either could not overcome the phonetic change, or failed to recognize the progressive verb tense of this high-frequency English head word, (\#215 in the General Service List). Demo and mansion, however, are both nouns, and are more phonetically similar to their Japanese counterparts デモ/demo and マンション /manshon. Interestingly, these two words were the only items on the entire word list which could not be located on both the General Service List and the British National Corpus. Though the words met all other primary criteria for target word selection (semantic properties, lexical word class, and verb-collocational behaviors), demo did not appear on the GSL, and mansion did not appear on either the GSL or BNC. Thus, it is possible that participants had never seen these two words in English before, rather than purposefully avoiding them. In addition, it is also possible that while participants recognized the phonetic similarity of all three words to lexicon in their L1, they may have been aware of semantic differences between cognates in general. This awareness may have steered these learners away from making an overly simplistic assumptions on the English word meaning, based on knowledge of the word's meaning in their L1.

In answering the second research question of which sentences would be more semantically accurate, it was found that sentences with non-true cognates were more likely to yield errors than true cognates. Participants were correct only $62.3 \%$ of the time with non-true cognates, versus $86 \%$ of the time with true 
cognates. Although these learners were at an intermediate level in their English studies, L1 interference was still having a large effect on these students' ability to use these words in semantically correct ways in context. Due to the test scores these students needed to gain entrance into their collegiate program, and considering that students had been in the US for at least four-five months, these participants should be at or above the $60^{\text {th }}$ percentile of Japanese ESL/EFL students. Although cognates have been thought to be most beneficial to beginners (Daulton, 2008), these data demonstrate that non-true cognates can still be problematic for students at later stages of learning. This finding could influence future pedagogy in terms of when to introduce various types of cognate learning activities.

In answering the third research question of whether participants make more syntactic errors with true cognates than non-true cognates, no relationship was found between cognate status and syntactic errors. As a percentage, there were only slightly more syntactic errors with true cognates (77.1\% accuracy) than with nontrue cognates (78.1\% accuracy). The closeness of these percentages is important. These results contrast with Masson's finding that true cognates create more syntactic interference than non-true cognates.

The difference in the results of my study versus Masson's could be attributed to format. Because it was unclear whether Masson's participants had to write sentences that were evaluated for syntax, even when participants did not demonstrate correct knowledge of semantics, it is possible that the difference may have led to more syntactic errors in that study. The instrument of the present study, 
however, controlled for this variable by clearly outlining which sentences would be evaluated for syntax, namely, only the sentences that demonstrated correct semantic knowledge. In addition, because Masson's survey had participants declare that they knew more than one meaning of a word, it is possible that participants did not accurately convey their word knowledge- some words may have had only one definition, and participants were not able to write a sentence if they only knew one definition. The present study controlled for this by setting one definition of a word as evidence of sufficient word knowledge. Finally, where Masson's study had participants provide a single answer for receptive and productive knowledge (Answer (3) I know more than one meaning of this word and I can use it in a sentence), the instrument of the present study allowed participants to support their receptive knowledge statement by providing a discrete translation of the word. In answering the third research question on what kind of semantic errors would be found from the sentences, it was determined that over $80 \%$ of total errors in semantics were attributed to imposition of Japanese meaning onto English meaning, or negative transfer. Negative transfer among only non-true cognates accounted for over $90 \%$ of semantic errors. This high percentage of L1 interference is noteworthy. Participants clearly overestimated their actual word knowledge, which is also in line with Masson's (2013) findings. These overestimations were usually caused by one issue - mistaking an English meaning for a Japanese meaning. These results show that semantic mastery of non-true cognates is a large problem for these students. Regardless of syntactic problems, we as educators 
cannot begin to assist Japanese learners with syntactic contextualization issues until they more fully understand the various forms of semantic drift of loanwords.

In answering the fourth research question of what types of syntactic errors participants will make, there was no pattern of errors pertaining to cognates that does not pertain to other types of English word learning among Japanese ELLs. That is, errors of cognacy were not unique. Eight categories found in this study (collocations, pluralization, articles, subject-verb agreement, word form, countability, tense, and word order) have been noted in other research, most notably, Ian Thompson's chapter on Japanese learners from Michael Swan's Learner English: A practical guide to interference and other problems (2002).

In answering the second half of this research question pertaining to frequency of error types, however, the data of the present study paints a more nuanced picture. Though none of the error types discovered here were new, it is important to look at the quantity of collocational issues across both cognate types. The qualitative analysis revealed that $38.5 \%$ of all error types were collocational. Considered in light of Masson's (2013) finding on collocations as one of the major error types, this data supports that claim in terms of which syntactic issue is most likely to create problems for cognates in general. When analyzed per cognate status, however, Masson's major finding was not supported. There was no statistically significant difference in the number of syntactic errors between true and non-true cognates. 
In addition, the qualitative analysis on collocational-syntactic errors per cognate status did yield a difference. True cognate collocational difficulties were most often caused by problems with prepositions, while non-true cognate collocational difficulties were most often caused by problems with verbs. This difference may be due to broad and productive Japanese verbs like する/suru (to do) and とる/toru (to take) being harnessed by non-experts (the general public) for everyday expressions. Because these two Japanese verbs are so broad, then can be readily accessed and easily paired with a variety of words. True cognates, on the other hand, are generally used by experts, and due to necessary precision of meaning, are less likely to be misused with liberal Japanese verbs.

\subsection{Pedagogical Implications}

By comparing semantics and syntax of true and non-true cognates, the results of this study may be used in creating the most helpful Japanese-English cognate teaching materials to date. There are four major takeaways from the present study:

- L1 semantic interference of non-true cognates is still problematic, even among intermediate learners.

- True and non-true cognates lead to similar numbers of syntactic difficulties; therefore the syntactic learning burden may not be a factor when considering how to teach contextualized output of true and non-true cognates. 
- Collocational difficulties were by far the most common error type for both cognate types.

- Collocational difficulties for true cognates were most often caused by prepositions, while collocational difficulties for non-true cognates were most often caused by verbs.

The findings above can serve curriculum developers and educators in structuring long-term learning arcs for their students, as well as creating individual lesson plans. In this section I will propose a curriculum for teaching cognates to Japanese learners of English, and propose individual activities to address each type of word knowledge.

When planning a long-term curriculum, I recommend first providing an overview of both cognate types to give learners a fundamental understanding of the issues at hand. From there, a split curriculum would prioritize needs (semantics over syntax), and ease the learning burden by focusing on one language target at a time. I recommend teaching the semantics of non-true cognates before the syntax of true cognates. This would be followed by teaching syntax of non-true cognates, and finally, tying everything together. This curriculum flow is represented in Table 15 below. 
Table 15

Recommended Curriculum Flow for Teaching True and Non-true Cognates

\begin{tabular}{ll}
\hline & Non-true Cognate \\
\hline Stage 1 & True Cognate \\
Overview & Introduce both cognate types at the same time, outlining their \\
semantic similarities and differences.
\end{tabular}

Stage 2

Semantics

Stage 3

Syntax

Stage 4

Syntax

Stage 5

Semantics + Syntax
Begin teaching semantic continuum of non-true cognates. Show learners how words can change from their English origins, converge, and diverge in Japanese.

As learners are still acquiring principles of semantic drift, delay this step.
Once learners are made aware of which types of words are true cognates, they can skip this step because word meanings will generally be the same as those in their L1.

Begin teaching syntactic output of true cognates. As meanings are generally understood already, ease the learning burden by focusing on syntax of words that learners already know.

\section{Begin teaching syntactic} output of non-true cognates. Learners should be comfortable with semantic drift and frequent collocational issues with true cognates at this point.

Tie it all together. Review semantics and syntax of true and non-true cognates, then expand into acquiring more vocabulary. 
In Stage 1, the primary purpose of lessons should be awareness raising. It is possible that students will enjoy true cognates, as these word can be used for confidence building (Daulton, 2008). In addition, students might be fascinated by non-true cognates because their meanings can be so different between the two languages. Learners should be made aware of the sociolinguistic functions of both cognate types - namely, true cognates are often academic and technical jargon, while non-true cognates tend to be more everyday expressions disseminated through mass media (Daulton, 2008; Hogan, 2010; Mckenzie, 2008).

Once learners understand the reasons why cognates change or remain the same, they will then have a framework for confronting the actual changes that can occur. In this stage, I recommend using flow charts that teach learners to make educated guesses of a word's meaning, based on its status in Japanese. If a word is an academic/scientific/technical term in Japanese, it is likely to carry that same meaning in English. If a word is more of an everyday expression, than it has greater potential of semantic drift between the two languages. Thus, flow charts could consist of such questions as: What does this word mean in Japanese? Is this an academic/scientific/technical term? Is this word on the Academic Word List? Is this an everyday term? Learning to think this way would assist learners in exercising appropriate caution around unknown future words, as well as knowing when to trust their L1 instincts. Because true cognates share the same meaning in both languages, Japanese speakers can usually harness this "built-in lexicon" (Daulton, 2008). If a learner can identify the corresponding Japanese mate to the English 
source word, and recognize that a word may be a true cognate, then it is highly likely that the learner will already know the English meaning. This process can be used to build confidence in technical and academic vocabulary, as well as to teach inferencing skills for unknown English word recognition. Students would continue to gain practice with these inferencing skills as they move through each stage of the curriculum.

In Stage 2, it may be best to focus on the semantic differences of non-true cognates. Because the present study revealed semantic interference of non-true cognates to be the most problematic issue in this entire study, this issue should be prioritized. Non-true cognates deserve ample attention when it comes to acquiring word-level meanings. We cannot support learners with syntax until they first appropriately understand common semantic pitfalls. Nuanced lessons should be created on the varied ways that meanings can change between the two languages. Examples should be provided of each non-true cognate type, according to Uchida's semantic taxonomy (as cited in Daulton, 2008). As a learner of Japanese, I always found non-true cognates to be particularly interesting, and it is possible that motivated Japanese learners of English would have a similar take.

As each non-true cognate has its own "story," it is likely that focused cognate learning will be highly salient for students. Jigsaw activities and dialogue writing could be utilized for these words. Groups of students could receive lists of words, based on frequency, and be tasked with researching their English meanings. This would allow students to work together and share in the surprise that some of these 
words offer. Students could have their work verified by the teacher, then teach these words to their peers. Jigsaw activities would also provide opportunities for L2 practice, and allow students to negotiate meaning with one another. Though due to the nature of cognates, the use of L1 might also be encouraged.

In addition, students could be instructed to write dialogues around the words. The purpose of the dialogues could be to highlight the differences in meaning, which affect comprehensibility and can often lead to humorous misunderstandings in spoken conversation. For example, a Japanese learner of English might say, Japanese people love to eat vikings. If an English-speaking interlocutor were unaware that viking is the transliteration of the Japanese word baikingu, which is a wasei-eigo word chosen for its Scandinavian-imagery to represent smorgasbord (which would be nine syllables in Japanese), then confusion and embarrassment would certainly occur. This activity could be fun and creative, allowing learners to delight in the idiosyncratic usages that these words can take on in their L1.

In Stage 3, learners would focus on the syntax of true cognates. Although the present study did not find a statistically significant difference in the number of errors between true and non-true cognates, sytntax of true cognates might nevertheless be prioritized in the curriculum in order to ease students' learning burden. While learners are still overcoming the range of semantic differences of non-true cognates, they can begin to explore the syntactic changes necessary to use true cognates appropriately in sentences. As prepositional collocations were found 
to be especially problematic for true cognates, word chunks with prepositions should be taught explicitly.

As L1 interference is often the culprit for syntactic difficulties, contrastive analyses could be undertaken with explicit awareness raising that draws attention to L1-L2 differences. Through worksheets, students can be asked to fill in certain criteria including: In what syntactic environments does this word appear in Japanese? What are common Japanese prepositions, particles, and verbs that co-occur with this word? How are those words different from similar English words? How can syntactic frames change between Japanese and English? The very act of noticing syntactic environments within texts can be beneficial for students. These comparisons would allow students to see the differences between Japanese and English usages, and perhaps pick up on common themes.

For materials, corpora can be utilized in the classroom. Students could be instructed on how to search for collocates, and compare frequency levels among various word strings. Once they are practiced enough in using a corpus, students can refer back to this valuable tool as they make choices in their own writing. Being able to see quantifiable spoken and written examples of English word usages will allow students to think critically and make more accurate decisions around meaning.

Once students see how a cognate is used in English, they can start to compile personal terminology checklists (Riley \& Sours, 2014). Every time a student comes 
across an English cognate that they are unfamiliar with, the following chart (Figure 9) could be filled out:

For each term, include:

grammatical category (noun, verb, etc.) a definition (from a dictionary or in your own words) an example in a sentence grammatical patterns you observe in texts or dictionaries collocations you observe in texts or dictionaries a translation into Japanese (if needed) any other information that interests you

Figure 3. Personal Terminology checklist, adapted from Riley and Sours (2014)

This type of checklist would allow learners to take the next step after noticing.

Students would write examples of the word in a sentence, grammatical patterns, and common collocations (prepositional, verbal, set phrases, etc.). This process of recording their findings would reinforce new knowledge. As the checklists contain meta-linguistic vocabulary (nouns, verbs, collocations, etc.) these grammatical points will also be reinforced. Students can alphabetize the words in binders, providing them with quick and ready access to a set of words that can be studied and reviewed in the future. Over time, these lists can assist students in shoring up previously learned vocabulary, as well as develop stronger intuitions in their interlanguage. 
In Stage 4, students would begin to work on contextualization of non-true cognates. At this point, students would have already learned the semantic properties of many non-true cognates. Having experience with contextualization of true cognates in Stage 3 will benefit students as they approach contextualization issues of non-true cognates. As verbal errors were found to be the most difficult collocational error type in the present study, these structures should be emphasized at the stage. L1-L2 comparative analyses, use of corpora, and personal vocabulary checklists may once again be utilized.

Finally, in Stage 5, all aspects of cognate learning could be brought together. Previously learned true and non-true cognates may be reviewed, and students could be assessed in their output of these words. Such testing could consist of an openended essay format: Tell me everything you know about this word, Explain the differences in meaning of this word between Japanese and English; multiple choice: Which of these prepositions does this word not commonly co-occur with?; and short answer: Use this word to mean two different things by pairing it with two different prepostions/verbs. In addition, inferencing skills could continue to be reinforced, with the introduction of lower-frequency English words that learners have not likely encountered before. Making educated guesses and knowing when to trust or distrust Japanese versions of English words are valuable skills that students can build over time.

Curriculum designers and educators would be squandering a useful resource of this in-built lexicon by ignoring Japanese-English cognates in the classroom. By 
explicitly drawing learners' attention to this shared vocabulary, teachers can tap into preexisting knowledge that learners bring to the table. The proposed curriculum flow in Table 15 above offers suggestions on which words to prioritize, and when new types of learning should be undertaken. Relevant adjustments could be made to this curriculum as well. In an English for Academic Purposes (EAP) context, teachers may first wish to provide their learners with lots of experience around the true cognates of the Academic Word List (AWL). In a conversational English class, however, students may wish to spend more time on the words that will cause problems with intelligibility with native speakers. The specific activities described: flowcharts, jigsaws, dialogue writing, contrastive analyses, use of corpora, and personal terminology checklists could all be applied in a variety of contexts.

\subsection{Limitations, Areas for Future Research, and Conclusion}

There are limitations of the present research. These include: participants' potential awareness of cognate status on the survey, and participants using other lexical word classes than the ones specified when writing the words in context. I will address the ways in which each of these problems may have had an effect, as well as possible steps to mitigate these issues in future studies.

As the word list for this study consisted entirely of cognates, it is possible that learners eventually picked up on this trend. After answering a few survey questions, learners may have become hyper aware that the target words were all cognates to Japanese words, and discerned that the purpose of the study was 
somehow related to cognates. If this was the case, participants may have begun immediately translating words into Japanese before fully thinking through their English meanings. This effect may have had a particular effect on non-true cognates, where meanings between Japanese and English are always different in some way. 1:1 meaning relationships may have become the first phase of participants' comprehension, and led to survey answers that were not fully thought out.

In the future, a survey which includes non-cognates would mitigate the aforementioned issue. There would be no cognate awareness effect because not all survey words would be cognates. This type of survey would build directly on the work of as Rogers, Webb, and Nakata (2014), which found that cognates created more syntactic interference than non-cognates. Statistical significance tests could be applied across all three word types (true cognates, non-true cognates, and noncognates) in order to more finely carve out the differences in learnability of these varied word categories.

Another limitation of this study was the way participants responded to the lexical word class designations of the target words. As mentioned in Section 3.2 Target-word Selection, there were cases where participants wrote a sentence with the target word as a different word class than the one specified in the instrument. I chose to keep this sentence data because I judged that using a word as different word class was still evidence of knowing a word. This methodological decision may have been limiting, however, because participants' answers were not bound to specific word classes. By having the freedom to use a word as any word class, errors 
were likely masked. In addition, it was possible that the word class chosen by the participant was a less frequent version of the word than the high frequency head words that were chosen from the AWL, AVL, GSL, and BNC. If learners happened to choose less frequent word classes that they did not know as well, then it is possible that learners may have produced less accurate sentences.

In the future, these variances could be controlled for with super-explicit instruction to students. The title page of the instrument could include examples which demonstrate the proper usage of the word according to word class, and an incorrect usage of the word used as a separate word class. In addition, lexical word class could be labeled in Japanese, but it would probably be better to label words in English as well. The metalinguistic English labels would likely play a role in activating the L2 framework within learners.

Other research that I would like to see could account for individual variation among participants and/or words. The amount of data and the potential for analysis here was tremendous. The chi square frequency test was valuable in looking at overall relationships according to cognate status, but does not make it possible to look at variation either of individual participants or of test items. I did notice certain trends when evaluating specific words and even among specific participants, but any observations I could make from the present study would only be anecdotal. A future study that accounts for individual differences may shed light on which individuals made which types of errors, or more importantly, which words were usually evaluated as correct/incorrect, etc. 
I would also like to see research that evaluates the effectiveness of a cognate treatment program in the classroom. To date, there have been no studies that have analyzed performance improvements of Japanese learners of English when it comes to cognate learning. Control and experimental student groups could be established, and improvements in cognate acquisition could be compared over time. In addition, it would be interesting to look at how students confront brand new cognates after having developed learning strategies from other cognates. The purpose of teaching cognates should not only be to encourage mastery of a discrete set of vocabulary words, but to also train learners in ways of thinking that they can access toward fully acquiring unknown words in the future.

Cognates provide a unique opportunity for Japanese learners of English. Although the two languages are quite different in their orthography, grammar, sound systems, and linguistic roots, there are also striking similarities between the two languages. Loanwords can provide a quick and ready "bridge" from Japanese to English. Experts in advanced academic and technical fields harness loanwords to communicate with one another and educators can use loanwords to build confidence at the beginning stages of learners L2 acquisition. Yet loanwords also have a dark side. Non-true cognates can create confusion in everyday situations due to their semantic drift. Due to this paradoxical nature, cognates have rarely been used in the classroom with Japanese learners. It is my hope that the present research has provided a fuller picture of the specific nuances of Japanese-English 
cognate learning, and that the results contained may be a launching point to harness the power of Japanese-English cognates in the classroom. 


\section{References}

Bauman, J. (n.d.). About the general service list. Retrieved from http://jbauman.com/gsl.html.

Biber, D., Conrad, S., \& Leech, G. (2013). Student grammar of spoken and written English. Harlow, Essex: Longman.

British National Corpus. (n.d.). Retrieved from www.natcorp.ox.ac.uk.

Bultena, S., Dijkstra, T., \& van Hell, J. (2014). Cognate effects in sentence context depend on word class, L2 proficiency, and task. The Quarterly Journal of Experimental Psychology, 67 (6), 1214-1241.

Cambridge Institute. (n.d.). Score comparison for English levels. Retrieved from http://www.cambridgeinstitute.net/en/tests-de-nivel-ingles/test-nivelingles-i/nivel-ingles-test-ingles.

Champ, N. (2014). Gairaigo in Japanese foreign language learning: A tool for native English speakers? New Voices, 6, 117-143.

Davies, M. (2008). The Corpus of Contemporary American English (COCA): 520 million words, 1990-present. Retrieved from http://corpus.bye.edu/coca/.

Daulton, F. (2003). List of high-frequency baseword vocabulary for Japanese EFL students \#2. The Internet TESL Journal, 9(3). Retrieved from http://iteslj.org /lists/Daulton-BasewordVocab2.html.

Daulton, F. (2005). Common gairaigo corresponding to high-frequency and academic English—Are Japanese students ready for foreign study? JALT Hokkaido Journal, 9, 1-16. 
Daulton, F. (2008). Japan's built-in lexicon of English-based loanwords. Clevedon: Multilingual Matters.

Daulton, F. (2011). On the origins of gairaigo hias: English learners' attitudes toward English-based loanwords in Japan. The Language Teacher 35(6). 7-12.

Gardner, D. \& Davies, M. (2014). A new academic vocabulary list. Oxford University Press 35(3). 305-327.

Hogan, J. (2010). The social significance of English usage in Japan. Japanese Studies. 23(1), 43-58.

Kelley, A., \& Kohnert, K. (2012). Is there a cognate advantage for typically developing Spanish-speaking English-language learners? Language, Speech and Hearing Services in Schools, 43 (2), 191-204.

Masson, E. (2012). Student feedback regarding the use of 'mastery sentences.' Vocabulary Education and Research Bulletin 1 (1), 5-6.

Masson, M.E. (2013). How L1 loanwords can create a false sense of familiarity with L2 vocabulary meaning and usage. Vocabulary Learning and Acquisition, 2 (1), 8-14.

Mckenzie, M. (2008). The complex and rapidly changing position of English language in Japan: A summary of English language contact and use. Japan Forum 20(2), 267-286.

Montelongo, J., \& Hernandez, A. (2013). The teachers' choices cognate database for K-3 teachers of Latino English learners. The Reading Teacher, 67 (3), 187192. 
Nation, P. (2001). Learning vocabulary in another language. Cambridge: Cambridge University Press.

Nation, P. (2013). Commentary on four studies for JALT vocabulary SIG. Vocabulary Learning and Instruction 2(1), 32-38.

Ozaki, S. (2011). Teaching collocations effectively with the aid of L1. The Language Teacher 35 (3), 37-40.

Paribakht, T. \& Wesche, M. (1993). Reading comprehension and second language development in a comprehension-based ESL program. TESL Canada Journal, $11(1), 9-29$.

Riley, A \& Sours, P. (2014). Common law legal English and grammar: A contextual approach. Oxford: Hart Publishing.

Rogers, J., Webb, S., \& Nakata, T. (2014). Do the cognacy characteristics of loanwords make them more easily learned than noncognates? Language Teaching Research. 1-20. doi: 10.1177/1362168814541752

Shin, D. \& Nation, P. (2007). Beyond single words: the most frequent collocations in spoken English. ELT Journal 62 (4), 339-348.

Stanslaw, J. (2004). Japanese English: Language and culture contact. Hong Kong: Hong Kong University Press.

Thompson, I. (2001). Japanese speakers. In Swan, M. (Ed.) Learner English: A teacher's guide to interference and other problems. (pp. 296-309). Cambridge: Cambridge University Press. 


\section{Appendix A:}

\section{Instrument Title Page in English}

\section{Vocabulary Survey}

For each of the following words, please circle the number that shows your level of understanding of that word.

- If you circle \#1 or \#2, DO NOT WRITE A SENTENCE.

- If you circle \#3, PLEASE WRITE A SENTENCE.

Here is an example:

Contract

1. I have never seen this word.

2. I have seen this word before, but I don't know what it means.

(3.) I have seen this word before, and I think it means

official paper/契約 (synonym or translation).

I circled \#3. This is the word in a sentence:

When I signed the contract, I became the owner of the house.

- If you write a sentence, please create a sentence that demonstrates your FULL understanding of the word.

- Please write a sentence using the key word that clearly shows the meaning of the word and can only be replaced by a direct synonym.

Key word: Contract

GOOD SENTENCE

When I signed the contract, I became the owner of the house.

POOR SENTENCE

I like contracts.

- The good sentence shows what the word means; it is the only word that can fit in that sentence and make sense. The poor sentence does not show what the word means. Any word could fit in that sentence. 


\section{Appendix B:}

\section{Instrument Title Page in Japanese}

\section{英単語知識に関する調查}

各単語に対して、最も当てはまる答え1つに丸をつけてください。

・ 1 番、もしくは 2 番に丸をつけた場合には、例文を記入せず、次の問題へ 進んでください。

・ 3 番に丸をつけた場合には、例文を記入してください。例文の書き方に ついては、下記をご参照ください。

例:

Contract

1. 見たことのない単語

2. 見たことのある単語だが、意味は分からない

3. 見たことのある単語で、意味は official paper/契約*だと 思う。

*赤線に英語の同類語、もしくは日本語訳をご記入ください。

3番に丸をつけられた方は、この英単語を使った例文を下記に ご記入ください：

When I signed the contract, I became the owner of the house:

例文をご記入いただく際には、下記の点にご注意ください：

・ 単語の意味、またその単語が文章にどのように組み込まれるかを理解しているこ とが、明確に分かる文章であること。下記の『悪い例文』のように、簡単に単語 を置き換えることが出来るような文章でないこと。

・指定の単語を使った場合のみ、意味の通じる文章であること。もし単語を代替し た場合、下記にある『良い例文』のように、意味に相違が生じる、または文章が 成り立たなく

なること。

単語: Contract

\section{良い例文}

When I signed the contract, I became the owner of the house.

悪い例文

I like contracts. 


\section{Appendix C}

\section{Consent Form}

\section{The Case of Japanese Learners of English \\ Participant Consent Form}

Andrew Sowers is conducting a study what words Japanese learners of English know and how they use them. This survey will be used for Andrew Sowers' Master's Thesis, The Case of Japanese learners of English. You are being asked to participate in this study because you are a Japanese speaker who is currently studying English.

\section{What Will I Have To Do?}

- You will be asked to take a survey about English words.

- The survey will ask whether you know the meaning of the word, and ask you to write some sentences.

- This survey will take about 30-45 minutes.

\section{Are There Any Risks?}

- There is a small risk that you will feel embarrassed because you do not know an answer.

- You will need to spend time taking the survey.

- You do not have to take part in this study. You don't have to answer any questions you don't want to. And if you don't want to go on, you can stop.

\section{What Will I Get In Return?}

- You will not receive any direct benefit, but you will help teachers like me better understand how students learn vocabulary when they are studying a language.

- You will be entered into a drawing for a $\$ 10$ gift card.

\section{What Are You Doing To Protect Me?}

- Your name will never be used in the research. No one who uses the information now or later will know your name or identifying information.

- Your teachers will not know your answers and the survey will not contribute to your course grade.

- We will not tell anyone whether you agreed to participate or not.

- This survey will be analyzed for those who agree to participate. The data will help us understand they ways that Japanese learners learn certain types of English vocabulary words.

- If you do not wish to take the survey, please check the 'no' box below. If you wish to take part, please check the 'yes' box.

- You will be given a copy of this consent form.

\section{Any Questions?}

If you have any questions, you can contact Andrew Sowers (sowersan@pdx.edu, 971-2841994), or his advisor Lynn Santelmann (santelmannl@pdx.edu, 503-725-4140). You can 
also contact the Office of Research Integrity of Portland State University about your rights as a research participant (someone who takes part in a study). Hours are 9:00 a.m. to 5:00 p.m. The office is located at Portland State University, Market Center Building, Ste. 620, Portland, OR 97201. The telephone number is (503) 725-2227.

\section{If I Sign, What Does It Mean?}

This is a consent form. Your signature below means that:

- You have read and understand what this form says.

- You are willing to take part in the study.

- You know that you do not have to take part in this study. And even if you agree, you can change your mind and stop at any time. No problem

- You will get a copy of this form to keep for yourself.

$\square$ Yes, I wish to participate

$\square$ No, I do not wish to participate

Signature

Date

Printed First name

Printed Last name

Administrator

Date

Student copy

Administrator copy 